\title{
Ensemble Kalman Filter Assimilation of Polarimetric Radar Observations for the 20 May 2013 Oklahoma Tornadic Supercell Case
}

\author{
BRYAN PUTNAM \\ Center for Analysis and Prediction of Storms, Norman, Oklahoma \\ Ming XUE \\ Center for Analysis and Prediction of Storms, and School of Meteorology, University of Oklahoma, Norman, \\ Oklahoma \\ YOUNGSUN JUNG AND NATHAN SNOOK \\ Center for Analysis and Prediction of Storms, Norman, Oklahoma \\ GUIFU ZHANG \\ Center for Analysis and Prediction of Storms, and School of Meteorology, University of Oklahoma, and Advanced \\ Radar Research Center, Norman, Oklahoma
}

(Manuscript received 17 July 2018, in final form 8 March 2019)

\begin{abstract}
Real polarimetric radar observations are directly assimilated for the first time using the ensemble Kalman filter (EnKF) for a supercell case from 20 May 2013 in Oklahoma. A double-moment microphysics scheme and advanced polarimetric radar observation operators are used together to estimate the model states. Lookup tables for the observation operators are developed based on T-matrix scattering amplitudes for all hydrometeor categories, which improve upon previous curved-fitted approximations of T-matrix scattering amplitudes or the Rayleigh approximation. Two experiments are conducted: one assimilates reflectivity $(Z)$ and radial velocity $\left(V_{r}\right)($ EXPZ), and one assimilates in addition differential reflectivity $\left(Z_{\mathrm{DR}}\right)$ below the observed melting level at $\sim 2-\mathrm{km}$ height (EXPZZDR). In the EnKF analyses, EXPZZDR exhibits a $Z_{\mathrm{DR}}$ arc that better matches observations than EXPZ. EXPZZDR also has higher $Z_{\mathrm{DR}}$ above $2 \mathrm{~km}$, consistent with the observed $Z_{\mathrm{DR}}$ column. Additionally, EXPZZDR has an improved estimate of the model microphysical states. Specifically, the rain mean mass diameter $\left(D_{\mathrm{nr}}\right)$ in EXPZZDR is higher in the $Z_{\mathrm{DR}}$ arc region and the total rain number concentration $\left(N_{\mathrm{tr}}\right)$ is lower downshear in the forward flank than EXPZ when compared to values retrieved from the polarimetric observations. Finally, a negative gradient of hail mean mass diameter $\left(D_{\mathrm{nh}}\right)$ is found in the right-forward flank of the EXPZZDR analysis, which supports previous findings indicating that size sorting of hail, as opposed to rain, has a more significant impact on low-level polarimetric signatures. This paper represents a proof-of-concept study demonstrating the value of assimilating polarimetric radar data in improving the analysis of features and states related to microphysics in supercell storms.
\end{abstract}

\section{Introduction}

Convective storms feature complex cloud microphysical and dynamical processes that interact to produce diverse microphysical states and structures [in terms of hydrometeors of different types and their particle size distributions (PSDs)] that vary widely within the storms. The highly

Corresponding author: Ming Xue, mxue@ou.edu nonlinear microphysical processes associated with diverse microphysical states can lead to rapid error growth in convective-scale numerical weather prediction (NWP) model forecasts even when only slight error exists in the model initial condition (Lorenz 1969; Larson et al. 2005; Wang et al. 2012). Data assimilation (DA) estimates the state of convective storms by optimally combining a background model state with available observations (Kalnay 2002). However, most studies assimilating 
radar observations of the observed microphysical states have thus far been limited to a single observed quantity: radar reflectivity $(Z)$. The national WSR-88D network has recently been upgraded to provide CONUS-wide coverage of polarimetric observations (ROC 2013), which had previously been available only from experimental radars. These polarimetric observations contain additional valuable information on microphysical states and can be used to improve the estimate of the model microphysical states for convective-scale models. In this study, we assimilate these polarimetric observations directly into a convective-scale model using the ensemble Kalman filter (EnKF) method (Evensen 1994, 2003) to improve the estimation of microphysical state variables associated with a double-moment (DM) microphysics parameterization scheme.

The polarimetric observations include differential reflectivity $\left(Z_{\mathrm{DR}}\right)$, which provides information on the horizontal-to-vertical axis ratio of hydrometeors (Seliga and Bringi 1976; Bringi and Chandrasekar 2001). Specific patterns of $Z_{\mathrm{DR}}$ values, often referred to as polarimetric signatures, can be used to identify hydrometeor types and sizes as well as important microphysical and dynamical processes in convective storms (Balakrishnan and Zrnić 1990; Zrnić et al. 1993; Brandes et al. 1995; Zrnić and Ryzhkov 1999; Loney et al. 2002; Scharfenberg et al. 2005; Kumjian and Ryzhkov 2008; Van Den Broeke et al. 2008). For example, one such polarimetric signature is an arc of high $Z_{\mathrm{DR}}$ values $\left(Z_{\mathrm{DR}}\right.$ arc) often seen in the forward flank of supercells, which is indicative of hydrometeor size sorting due to storm-relative wind shear (Kumjian and Ryzhkov 2008, 2012; Dawson et al. 2014).

The EnKF DA method is particularly well suited for direct assimilation of polarimetric observations due to its ability to deal with highly nonlinear observation operators and model physics, and its ability, through spatial covariances and cross covariances, to spread observed information beyond the regions where observations are taken and to correct errors in state variables that are not directly observed (Snyder and Zhang 2003; Tong and Xue 2005). Direct assimilation assimilates observations without prior retrieval and is a preferred approach for remotely sensed data such as satellite radiance and radar data.

An essential component for direct assimilation of any observation type is the observation forward operator, which links model state variables to the observed quantity. A polarimetric radar data (PRD) simulator, or its simplified version (for computational efficiency), developed by this research group serves as the observation operator. It is important that the formulations and assumptions of the PRD operators accurately replicate the interaction of the radar wave with hydrometeors of all reasonable types, sizes, and physical states because polarimetric variables are greatly impacted by how much energy is scattered from the horizontally and vertically polarized radar beams. Jung et al. (2008a) developed a set of PRD operators for a single-moment (SM) microphysics (MP) scheme that links the polarimetric variables with microphysical state variables, and includes an axisratio relation for raindrops, a melting model, and radar wave scattering amplitude functions fitted to T-matrix calculations for rain and the Rayleigh approximation for ice hydrometeors (Zhang et al. 2001). Xue et al. (2010) and Jung et al. (2010a) expanded on these operators by adding the ability to use multimoment (MM) MP schemes and numerical integrations of the scattering amplitudes calculated using the T-matrix method for all hydrometeors. The numerical integration methods, however, require lookup tables of precalculated scattering amplitudes and result in too high of a computational cost for DA purposes, and have thus far been limited to simulation of (Jung et al. 2010a; Johnson et al. 2016) and verification against PRD (Dawson et al. 2014, Putnam et al. 2017a,b).

For the assimilation of PRD, the EnKF should be paired with MM MP schemes, which predict both the mixing ratios (mass content) and number concentrations of hydrometeors. This allows for the independent prediction of the intercept parameter and slope parameter of the assumed gamma size distributions of hydrometeor particles (PSDs) (e.g., Milbrandt and Yau 2005a). This is particularly important because polarimetric variables are highly sensitive to the size distributions in MP schemes (Jung et al. 2010a, 2012; Dawson et al. 2014; Putnam et al. 2014; Johnson et al. 2016; Putnam et al. 2017a,b). For example, this includes the direct sensitivity between $Z_{\mathrm{DR}}$ and the oblate shape of raindrops and the indirect sensitivity between $Z_{\mathrm{DR}}$ and the size of a raindrop, which affects how oblate the drop is. Without the ability to properly simulate PSDs in the model, the linkage between PRD and the model states is likely broken, making the PRD assimilation ineffective.

The EnKF has been used successfully in assimilating real radar data across a variety of cases (e.g., Snook et al. 2011, Jung et al. 2012; Yussouf et al. 2013; Chang et al. 2014; Putnam et al. 2014; Wheatley et al. 2014; Snook et al. 2015, Yussouf et al. 2015; Snook et al. 2016). The EnKF statistically estimates error covariances among state variables within a background forecast from an ensemble and updates the state variables using observations in an optimal estimation framework. An adjoint model that involves linearization of the observation operators as in 3DVAR and 4DVAR, and of the nonlinear prediction model as in 4DVAR, is not needed. Development of an adjoint model is particularly difficult 
with nonlinear observation operators (such as those of PRD) and prediction models with complex MP schemes (e.g., multiphase MM MP). One initial concern when using the EnKF with a MM MP scheme is that the estimation of a larger number of state variables is underconstrained by using very few observed parameters [e.g., $Z$ and radial velocity $\left(V_{r}\right)$ from traditional Doppler radars]. However, Xue et al. (2010) encouragingly demonstrated the ability of the EnKF to update 10 microphysical state variables associated with a DM Milbrandt and Yau (2005a) MP scheme in the presence of model error. The assimilation of polarimetric observations can provide additional independent information to update the numerous microphysical state variables, helping to mitigate this concern.

Previous research on data assimilation using polarimetric observations is still very limited-both for observing system simulation experiments (OSSEs) and real observation experiments - and has not included the advanced operators and MP schemes needed to take optimal advantage of the polarimetric observations. Jung et al. (2008b) showed promise for polarimetric observation assimilation in an EnKF OSSE study that assimilated $Z_{\mathrm{DR}}$, radar reflectivity difference $\left(Z_{\mathrm{DP}}\right)$, and specific differential phase $\left(K_{\mathrm{DP}}\right)$ in addition to $Z$ and $V_{r}$ using the operators developed in Jung et al. (2008a). In their study, analyses assimilating additional polarimetric observations exhibited improved root-mean-square errors (RMSEs) for both microphysical state variables and all other model state variables. This study is the first to directly assimilate PRD into a model with multiphase ice microphysics.

Wu et al. (2000) represents the first attempt to assimilate real PRD. In their study, rainwater and graupel/ hail mixing ratios diagnosed from $Z$ and $Z_{\mathrm{DR}}$ observations were assimilated using 4DVAR (Sun and Crook 1997), and a cloud model with a simple ice MP scheme that included cloud water/cloud ice, rain, and graupel/ hail categories only. Reasonable analyses of the structure of a single cell storm were obtained, but forecasts quickly deteriorated. Li and Mecikalski $(2010,2012)$ assimilated rainwater mixing ratio $\left(q_{r}\right)$ preretrieved from real $Z_{\mathrm{DR}}$ and $K_{\mathrm{DP}}$ data using WRF 3DVAR, in addition to $Z$ and $V_{r}$, for a mesoscale convective system (MCS) and a mesobeta-scale thunderstorm; they found that the additional polarimetric data led to better shortterm predictions of storm structure and location. However, their studies used a simple SM warm-rain Kessler (1969) MP scheme. Yokota et al. (2016) also assimilated retrieved $q_{r}$ from $Z$ and $K_{\mathrm{DP}}$ using the local ensemble transform Kalman filter to predict a low-level mesocylone associated with a tornadic supercell in Japan, specifically finding that assimilating the radar variables led to increased low-level moisture and thus a better predicted low-level mesocyclone. However, in addition to the simplified retrieval methods, only a SM Lin MP scheme (Lin et al. 1983) was used. A more recent study by Li et al. (2017) directly assimilated $Z$ and $K_{\text {DP }}$ data for an MCS case using WRF 3DVAR and a simple ice MP scheme (Dudhia 1989; Rutledge and Hobbs 1983) that contained only cloud ice and snow above the freezing level and cloud water and rainwater below. Therefore, there was no coexistence of mixedphase hydrometeors except in a predefined melting layer. The observation operators for $Z$ and $K_{\mathrm{DP}}$ were functions of snow and rainwater mixing ratios only above the $-5^{\circ} \mathrm{C}$ and below $5^{\circ} \mathrm{C}$ temperature levels, respectively, and functions of the linear combinations of the two mixing ratios while in the transition layer.

The purpose of this paper is to examine, for the first time, the impact of directly assimilating polarimetric observations on the estimate of the model microphysical states associated with a true multimoment ice microphysics scheme for a real convective storm. A fully DM ice MP scheme is used with the EnKF utilizing advanced polarimetric radar observation operators based on scattering amplitudes calculated using the T-matrix method. A new lookup-table method to precalculate a portion of the forward operator is developed that accounts for Mie scattering for all hydrometeors during assimilation without increasing computational expense. In this study we focus on the analysis (estimation) of model states at the convective storm scale as it is important to first evaluate and understand the impact of assimilating polarimetric observations on this scale; the forecasts from the analyses can be more affected by forecast model and storm environment errors, which makes the evaluation of the impact of data assimilation more difficult. The remainder of this paper is organized as follows. Section 2 gives a brief overview of the 20 May 2013 Newcastle-Moore, Oklahoma, supercell case used in this study. In section 3, the prediction model and microphysics scheme used within the EnKF DA cycles, together with the radar data processing and DA experiments and their settings, are described. The new lookup table approach for polarimetric radar observation operators is detailed. The analyzed polarimetric variables and the estimated model microphysical states are evaluated in section 4. Section 5 provides concluding remarks, and a discussion of current challenges and future work.

\section{20 May 2013 Newcastle-Moore, Oklahoma, tornadic supercell case overview}

On 20 May 2013, an outbreak of tornadoes occurred across the southern Plains. Most notably, one supercell storm over central Oklahoma produced a tornado rated 
EF5 on the enhanced Fujita (EF) scale (WSEC 2006; Doswell et al. 2009) that traversed the southern Oklahoma City metropolitan area during the midafternoon hours (SPC 2016). At 1800 UTC 20 May, an upper-level low pressure system was in place over the north-central United States with a large region of strong, southwesterly flow at $500 \mathrm{hPa}$ extending southward to the southern plains, providing significant deep shear to support rotating updrafts. At the surface, a cold front stretched from an associated surface low in the northern Plains southward through Oklahoma, with a dryline intersecting the front just to the west of Oklahoma City. A broad and extremely moist warm sector existed ahead of this cold front/dryline intersection with mixed-layer CAPE values exceeding $3000 \mathrm{~J} \mathrm{~kg}^{-1}$ in many areas. Storms began to develop after 1800 UTC, including the parent storm of the Newcastle-Moore tornado, which developed just to the southwest of Oklahoma City, near the intersection of the cold front and dryline. The Newcastle-Moore tornado began shortly before 2000 UTC and lasted for over $40 \mathrm{~min}$, tracking through Newcastle, south Oklahoma City, and Moore, Oklahoma. Catastrophic EF5-rated damage was observed in Moore, and total damages were over 1 billion U.S. dollars (Burgess et al. 2014). For a more detailed discussion of the 20 May 2013 Newcastle-Moore tornado, the reader is referred to Burgess et al. (2014), Zhang et al. (2015), and Kurdzo et al. (2015). As the storm of interest occurred very near the operational WSR-88D radar KTLX at Twin Lakes near Oklahoma City, low-level polarimetric observations are available for this storm.

\section{Experiment configuration and settings}

\section{a. Prediction model and microphysics scheme}

For this study, we use the Advanced Regional Prediction System NWP model (ARPS, Xue et al. 2000, 2001, 2003). Briefly, ARPS is a three-dimensional, fully compressible, nonhydrostatic, multiscale NWP model. The state variables predicted include the three-dimensional wind components $(u, v$, and $w)$, pressure $(p)$, potential temperature $(\theta)$, water vapor mixing ratio $\left(q_{v}\right)$, and turbulent kinetic energy (TKE), as well as microphysical state variables as determined by the MP scheme used. Radiation is parameterized using the NASA Goddard Space Flight Center long- and shortwave radiation schemes while subgrid-scale turbulence is parameterized with a 1.5-order TKE-based scheme. The soil model includes two layers with parameterized surface fluxes for sensible and latent heat as well as moisture. Additional details on the model physics parameterizations are given in Xue et al. (2001, 2003).
The MP scheme used in this study is the DM version of the Milbrandt and Yau (2005a) MP scheme. Previous studies have shown that convective-scale models require advanced MM microphysics schemes (i.e., at least DM) to replicate important microphysical processes like size sorting (Wacker and Seifert 2001; Milbrandt and Yau 2005b) and the associated polarimetric signatures (Jung et al. 2010a; Kumjian and Ryzhkov 2012). In fact, Jung et al. (2010a) demonstrated in simulations of polarimetric variables using SM and DM MP schemes that the SM MP scheme could not replicate several polarimetric signatures, including the $Z_{\mathrm{DR}}$ arc. The MY DM scheme predicts mixing ratios for cloud water $\left(q_{c}\right)$, ice $\left(q_{i}\right)$, rain $\left(q_{r}\right)$, snow $\left(q_{s}\right)$, graupel $\left(q_{g}\right)$, and hail $\left(q_{h}\right)$ as well as number concentrations for these hydrometeor types $\left(N_{\mathrm{tc}}, N_{\mathrm{ti}}, N_{\mathrm{tr}}, N_{\mathrm{ts}}, N_{\mathrm{tg}}\right.$, and $\left.N_{\mathrm{th}}\right)$. The MY DM scheme assumes a gamma size distribution for these species and the shape parameter is assumed to be zero, which reduces to an inverse exponential distribution. The choice of a single fixed shape parameter value is difficult because studies have shown a wide range of potential shape parameter values exist in precipitation (Brandes et al. 2002). Additionally, previous studies have shown that the inverse exponential distribution in the DM MY scheme can replicate polarimetric signatures in supercells to a reasonable extent (Jung et al. 2010a, 2012).

\section{b. Experiment configuration and EnKF settings}

Many of the EnKF DA experiment settings in this study are inherited from Snook et al. (2016), which assimilated only reflectivity and radial velocity data for the same 20 May 2013 case. Some details of the configuration are summarized here. The model comprises $603 \times$ 653 grid points in the horizontal and a stretched vertical grid with 63 levels. The minimum vertical spacing is $50 \mathrm{~m}$ at the surface and the average vertical spacing is $425 \mathrm{~m}$. The horizontal grid spacing of $500 \mathrm{~m}$ is used to represent highly localized polarimetric value gradients, patterns, and signatures. Model terrain is interpolated from U.S. Geological Survey (USGS) data of 30-arc-s spacings. For reference, the experiment domain and observations of the storms of interest near Moore, Oklahoma, are plotted in Fig. 1.

The DA experiment timeline consists of a 30-min spinup ensemble forecast initialized at 1800 UTC followed by cycled EnKF DA over a 1.5-h period (Fig. 2). The initial ensemble of 40 members as well as external boundary conditions are obtained via interpolation from the $4 \mathrm{~km}$ storm-scale ensemble forecasts (SSEF) produced by the Center for Analysis and Prediction of Storms (CAPS) Spring Experiment (Kong 2013) initialized at 1200 UTC 20 May 2013. Storm-scale perturbations (Tong and Xue 2008) are created by applying a 


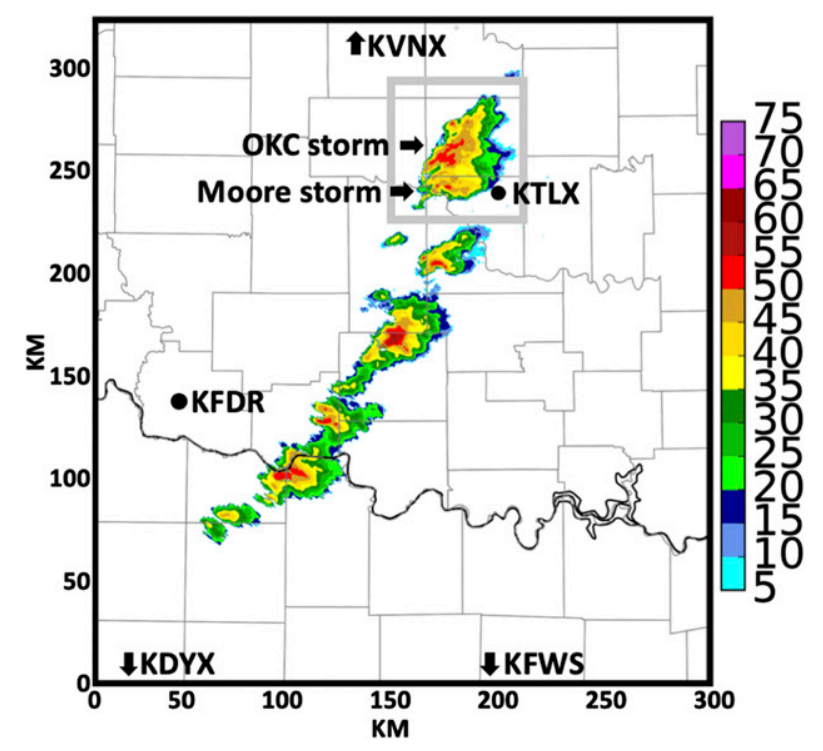

FIG. 1. 20 May 2013 experiment domain and location of radars assimilated. Observed reflectivity $(Z, \mathrm{~dB} Z)$ at the $0.5^{\circ}$ tilt from KTLX at 1938 UTC 20 May 2013 is included. The thin black line indicates the Oklahoma-Texas state boundary while the thin gray lines indicate county boundaries. The supercell associated with the Newcastle-Moore tornado is noted as the "Moore storm" and the supercell to the north discussed in the results is noted as the "OKC storm." The evaluation domain used in section 4 is noted by the thick gray box.

$2 \mathrm{D}$ recursive filter with a horizontal decorrelation length scale of $6 \mathrm{~km}$ to random, Gaussian noise; the smoothed perturbations are added to $u, v$, and the potential temperature $(\theta)$ fields. The mean standard deviation of $u$ and $v$ perturbations is $0.5 \mathrm{~m} \mathrm{~s}^{-1}$ and that of $\theta$ is $0.5 \mathrm{~K}$.

As described in Xue et al. (2006) and Snook et al. (2015), the ensemble square root filter (EnSRF, Whitaker and Hamill 2002) algorithm is used to assimilate both radar and surface observations at 5-min intervals from 1830 to 2000 UTC. Two experiments are conducted, one in which $Z$ and $V_{r}$ (as well as surface observations) are assimilated (EXPZ) and one in which $Z_{\mathrm{DR}}$ is also assimilated (EXPZZDR). The results of a test experiment assimilating $K_{\mathrm{DP}}$ are not included for this paper because of large uncertainties that exist in the $K_{\text {DP }}$ observations due to contamination from wet hail, dust and debris near the inflow region of the supercell, and potential nonuniform beam filling. Data are assimilated from five WSR-88Ds located in or near the model domain: KDYX, KFDR, KFWS, KTLX, and KVNX (see Fig. 1). Radar volume scans are assimilated based on proximity to each assimilation time. At each assimilation time, the volume scan that begins closest to the assimilation time within the previous 5-min forecast window is used, which guarantees that the volume scan will overlap the assimilation time. A few early cycles

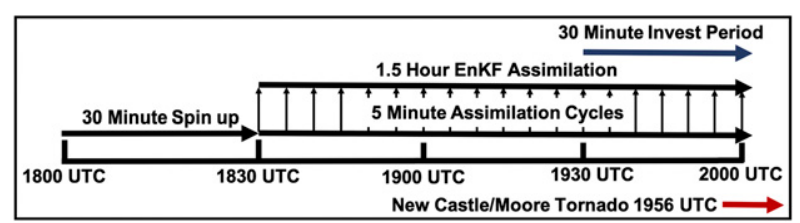

FIG. 2. Diagram of experiment timeline including the spinup forecast, assimilation window, 30-minute assessment period, and start time of the Newcastle-Moore tornado.

assimilate data from KDYX or KFWS every other cycle because these radars were initially in clear air mode and volume scans were $10 \mathrm{~min}$ apart. Additionally, observations slightly earlier than $5 \mathrm{~min}(7-8 \mathrm{~min})$ prior to assimilation for KDYX and KFWS are used in the first analysis at 1830 UTC.

We use assumed radar observation error standard deviations of $6 \mathrm{~dB} Z$ for $Z$ and $4 \mathrm{~m} \mathrm{~s}^{-1}$ for $V_{r}$ during EnKF DA, which are higher than those typically seen with these measurements (Doviak and Zrnić 1993; Ryzhkov et al. 2005). For our purposes, "observation error" includes measurement, sampling, and representativeness errors as well as error in the observation operator. These values were also determined to be optimal based on the work of Snook et al. (2013). The authors found that these higher error values led to increased ensemble spread and higher forecast skill based on statistical evaluation metrics including the area under the relative operating characteristic (ROC) curve (Mason 1982; Mason and Graham 1999) and forecast reliability diagrams (Brown 2001). Also, preliminary experiments using lower observation errors for $Z$ resulted in numerical instability in the ensemble forecasts. Estimated state and ensemble covariances can be relatively poor in early EnKF cycles and it is not desirable to fit observations too closely, which can result in unrealistically large innovation increments and cause model integration instability. Higher observation errors give less weight to the observations as well as account for the fact that observations are assumed to be unbiased and uncorrelated within the EnKF, which is not true for many cases.

Radar observations are assimilated at every other grid point (or at 1-km intervals; the radar data are first mapped to the model columns in the horizontal and kept on the elevation levels in the vertical-see section 3d) in precipitation regions as preliminary experiments found this configuration results in better model stability. Errors that originate from large uncertainties in the forecast model, forward operator, and grid spacing, among other potential sources, can result in large innovation increments and over adjustments in the model state that accumulate with denser observations. This is particularly 
important when multiple states are estimated for a DM MP scheme independently $\left(q\right.$ and $\left.N_{t}\right)$, where unrealistic combinations may occur (similar to estimating microphysical states and parameters simultaneously, see Jung et al. 2010b). $V_{r}$ observations are assimilated where observed $Z>10 \mathrm{~dB} Z$. Assimilation of clear-air $Z$ observations has been shown to help suppress spurious convection (Tong and Xue 2005); in this study, clear-air $Z$ observations are assimilated every 4 grid points (every $2 \mathrm{~km}$ ). The specifics of $Z_{\mathrm{DR}}$ assimilation are discussed in section 3c. Surface observations are assimilated from all available Automatic Surface Observing System (ASOS), Automatic Weather Observing System (AWOS), and Oklahoma Mesonet observation sites within the domain. These observations include $u, v, p$, air temperature $(T)$, and dewpoint temperature $\left(T_{d}\right)$. Assumed observation errors are $1.5 \mathrm{~m} \mathrm{~s}^{-1}$ for $u$ and $v, 2 \mathrm{~K}$ for $T$ and $T_{d}$, and $2 \mathrm{hPa}$ for $p$.

The covariance localization radii for radar observations are set to $3 \mathrm{~km}$ in both the horizontal and vertical directions using the correlation function of Gaspari and Cohn (1999). For the surface observations, the horizontal covariance localization radius is $300 \mathrm{~km}$ and the vertical radius is $6 \mathrm{~km}$. To maintain ensemble spread, the "relaxation to prior spread" covariance inflation method of Whitaker and Hamill (2012) is applied using an inflation coefficient of 0.95 (i.e., $95 \%$ of the prior spread is restored); this setting follows that of Snook et al. (2016).

\section{c. $Z_{\mathrm{DR}}$ observation assimilation settings}

In EXPZZDR, $Z_{\mathrm{DR}}$ observations are assimilated after the assimilation of $Z$ and $V_{r}$ observations is completed. $Z$ and $Z_{\mathrm{DR}}$ are highly correlated with the same microphysical state variables and thus most corrections are made to the same variables (Xue et al. 2010). The number of $Z_{\mathrm{DR}}$ observations assimilated is significantly less than $Z$ and $V_{r}$ and their values differ by an order of magnitude. The impact of $Z_{\mathrm{DR}}$ assimilation may be completely overwhelmed if $Z_{\mathrm{DR}}$ is assimilated immediately following each $Z$ and $V_{r}$ observation. In a perfect ensemble DA system, the order of assimilation should not matter, but in reality, the order in a serial EnKF system often matters due to needed covariance inflation and covariance localization, among other reasons. Preliminary experiments also found that assimilating $Z_{\mathrm{DR}}$ after $Z$ led to an improvement in both the root-meansquare innovation (RMSI) of the analysis in terms of $Z$, $Z_{\mathrm{DR}}$, and $V_{r}$ as well as the qualitative patterns of $Z_{\mathrm{DR}}$ values when compared to observations.

Additionally, we only assimilate $Z_{\mathrm{DR}}$ observations below $2 \mathrm{~km}$ above ground level (AGL) to avoid observations in the melting layer. Mixed-phase hydrometeors containing both liquid water and ice are not explicitly predicted in the numerical model; the model microphysics scheme instantly adds meltwater to rainwater. For this reason, water-coated ice in the melting layer is modeled in the observation operators based on the relative amounts of coexisting rainwater and dry ice; a fraction of rainwater and dry ice is taken out of pure rainwater and dry ice to form melting ice (Jung et al. 2008a). The modeling of melting ice in the operators adds additional uncertainties to the intensity of the melting signature, particularly because of melting snow which can vary significantly in terms of size, shape, and density (Brandes et al. 2007; Zhang et al. 2011). Future studies, including a follow-up study to Johnson et al. (2016), will investigate simulated polarimetric variables above the melting layer before they are used in our assimilation studies.

The assumed observation error standard deviation for $Z_{\mathrm{DR}}$ is set to $0.6 \mathrm{~dB}$, which is approximately twice the typical $Z_{\mathrm{DR}}$ observation error (Doviak and Zrnić 1993; Ryzhkov et al. 2005), to be consistent with the specified observation errors for $Z$ and $V_{r}$ and account for errors in the observation operator. A preliminary experiment using the typical measurement error of $0.3 \mathrm{~dB}$ had similar RMSI values for the ensemble mean analyses for $Z_{\mathrm{DR}}$ but increased RMSI values for $Z$. Only values of $Z_{\mathrm{DR}}>0.3 \mathrm{~dB}$ are assimilated, following thresholds determined in Jung et al. (2008b). Their comparison of simulated errors in $Z$ and $Z_{\mathrm{DR}}$ indicated that there is no discernable independent information from $Z_{\mathrm{DR}}$ values below this threshold due to noise.

\section{d. Radar data processing}

The presence of ground clutter and other biological scatterers can cause contamination of $Z$ and polarimetric observations (Zrnić and Ryzhkov 1998; Friedrich et al. 2009). Fortunately, the impacts of such contaminants on $Z$ are low enough compared to $Z$ values due to precipitation in this case to have very little impact on the analysis. For $Z_{\mathrm{DR}}$, however, returns from nonmeteorological targets are well within the range of typical values seen in precipitation and must be removed. We apply the Park et al. (2009) hydrometeor classification algorithm (HCA) to identify and remove observations determined by the HCA to be contaminated by ground clutter or biological scatters. Their $Z$, $Z_{\mathrm{DR}}$, cross-correlation coefficient $\left(\rho_{\mathrm{hv}}\right)$, standard deviation of $Z$ [SD(Z), 1-km running average], and standard deviation of differential phase $\left[\mathrm{SD}\left(\Phi_{\mathrm{DP}}\right), 2-\mathrm{km}\right.$ running average] membership functions are used for this purpose. Low $\rho_{\mathrm{hv}}$ values have been previously used to identify observations potentially containing large errors or nonmeteorological echoes in many studies (e.g., Ryzhkov and Zrnić 1998; Zrnić and Ryzhkov 1999; Gourley et al. 2007; 


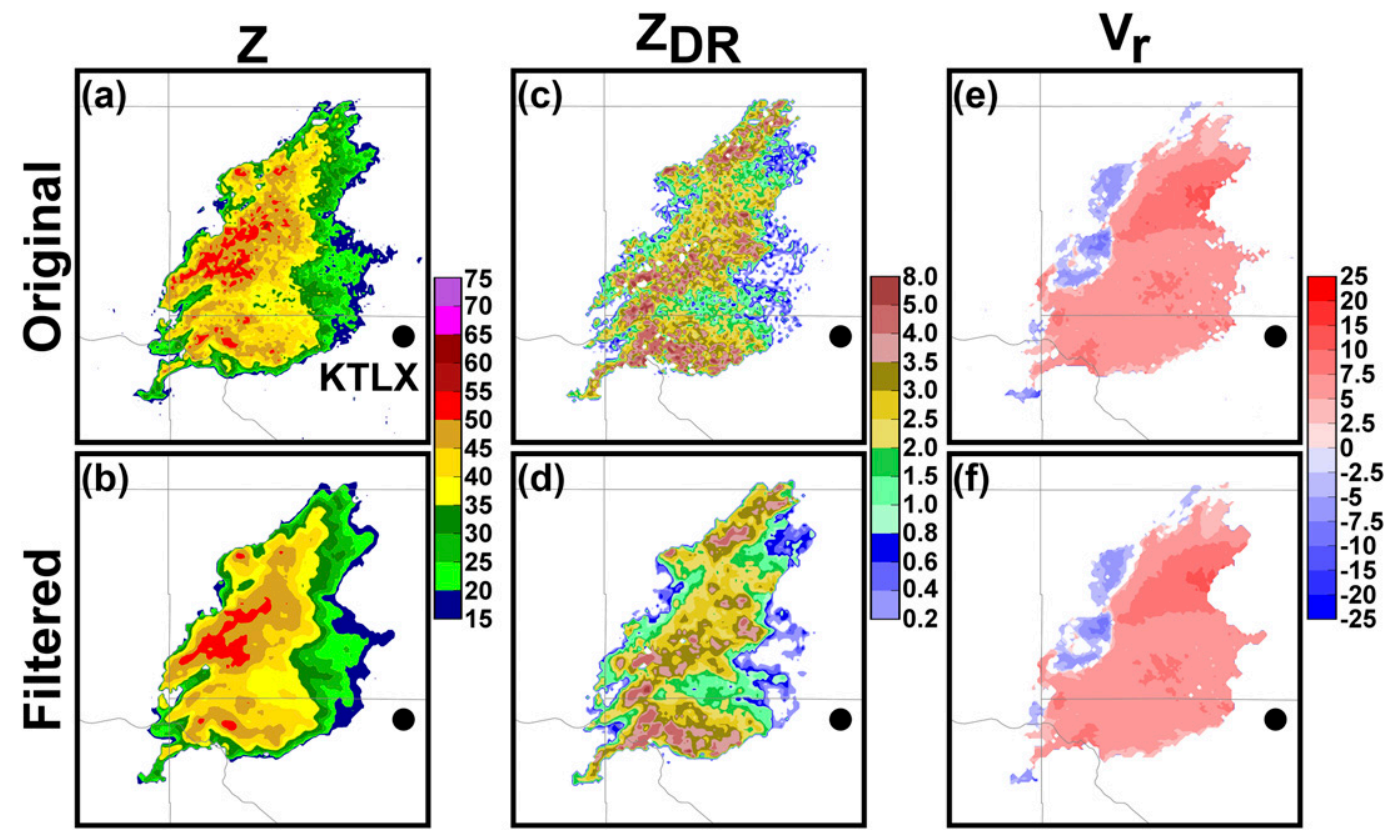

FIG. 3. Example of (a),(b) $Z$, (c),(d) $Z_{\mathrm{DR}}$, and (e),(f) $V_{r}$ observations from the $0.5^{\circ}$ tilt of KTLX (location noted by the black circle) at 1940 UTC (top) before and (bottom) after spatial filtering.

Lakshmanan et al. 2014). For this case, many $\rho_{\text {hv }}$ values are also particularly low in the convective regions, with values less than 0.8 . These low values are potentially due, at least partially, to nonuniform beam filling (Ryzhkov 2006; Kumjian 2013). These questionable observations are effectively removed by the HCA algorithm in our case.

Other preprocessing of the radar data includes automatic velocity de-aliasing (Brewster et al. 2005). Observations are interpolated to the model grid columns in the horizontal, but are left at the height of the radar tilt elevation in the vertical (Xue et al. 2006). Spatial filtering on the observations helps reduce random measurement error in the $Z_{\mathrm{DR}}$ field and lower the RMSIs of $Z$ and $Z_{\mathrm{DR}}$. Therefore, a five-point median filter is applied to $Z$ and $Z_{\mathrm{DR}}$ along each radial of radar data (at gate spacings of $250 \mathrm{~m}$ ) before interpolation to the model grid columns and a nine-point square median filter is applied to the interpolated values. An example of $Z, Z_{\mathrm{DR}}$, and $V_{r}$ observations at 1940 UTC before and after the filtering methods are applied is given in Fig. 3. In particular, the filtering removes a lot of noise from the $Z_{\mathrm{DR}}$ observations while preserving overall patterns and signatures including the $Z_{\mathrm{DR}}$ arc.

\section{e. Observation operators}

Our previous studies (e.g., Jung et al. 2012; Putnam et al. 2014) have used the polarimetric observation operators originally developed in Jung et al. (2008a), which include an axis-ratio relation to model oblate raindrops and a melting model to approximate the fraction of water coating frozen hydrometeors when predicted rain and frozen hydrometeors coexist. These operators also use a fitted approximation to T-matrix scattering amplitudes (Vivekanandan et al. 1991; Bringi and Chandrasekar 2001) for rain and the Rayleigh approximation for ice hydrometeors. A more advanced set of operators was developed in Jung et al. (2010a), including an updated axis ratio for rain (Brandes et al. 2002, 2003) that improves upon the prior relation by approximating more spherical shapes. Additionally, full T-matrix scattering amplitudes calculated for a range of diameters for all hydrometeor categories were used. The new operators lead to more realistic simulated polarimetric values. For example, $Z_{\mathrm{DR}}$ values with these operators are lower compared to those from the prior operators due to the revised axis-ratio relation for rain. The $Z$ values are also better approximated for large, melting hail where Mie scattering is a factor for S-band radars. However, due to the new axis ratio relation and table of scattering amplitudes, these operators require computationally expensive numerical integration over the PSD.

A modified set of the observation operators from Jung et al. (2010a) has been developed to increase computational efficiency with minimal sacrifice to accuracy. A portion of the operator is computed based on ranges of possible PSD parameter values prior to assimilation and stored in lookup tables to speed up the calculation 
during assimilation. Lookup tables have been used previously to increase computational efficiency for model parameterization schemes (Pielke et al. 2006). For example, tables have been used in microphysics schemes for precomputing ice particle size distribution moments for melting (Morrison and Milbrandt 2015), converting rain and snow into graupel based on particle size (Thompson et al. 2008), and ice nucleation rates (Morrison et al. 2005), Lookup tables have also been used to retrieve observed snow content and snowfall rate based on reflectivity (Liao et al. 2016). For this application, the tables are based on the slope $\left(\Lambda_{x}\right)$ and shape $\left(\alpha_{x}\right)$ parameters of the PSD. In this experiment, only $\Lambda_{x}$ is considered since $\alpha_{x}=0$ for all hydrometeors during assimilation. As an example, the horizontally polarized radar reflectivity $Z_{h h}$ (generally discussed as $Z$ ) observation operator for rain is given as:

$$
Z_{h h}=\frac{4 \lambda^{4}}{\pi^{4}\left|K_{w}\right|^{2}} \int\left|f_{a}(\pi)\right|^{2} N_{0} e^{-\Lambda D} d D,
$$

where $\lambda$ is the wavelength of the radar, $K_{w}$ is the dielectric factor for water, $f_{a}(\pi)$ is the backscattering amplitude along the major axis, $N_{0}$ is the intercept parameter, $\Lambda$ is the slope parameter, and $D$ is diameter [adapted from Eq. (3) from Jung et al. (2010a)]. For reference, in Jung et al. (2008a), when a fitted approximation to the T-matrix scattering amplitudes is used, a power law function is used in place of $\left|f_{a}(\pi)\right|$. Next, a summation over raindrop diameters from 0.0 to $8.0 \mathrm{~mm}$ in increments of $\Delta=0.8 \mathrm{~mm}$ is computed:

$$
Z_{h h}=\frac{4 \lambda^{4}}{\pi^{4}\left|K_{w}\right|^{2}} N_{0} \sum_{i=0.0}^{8.0}\left|f_{a}(\pi)\right|^{2} e^{-\Lambda D} \Delta D .
$$

$N_{0}$ can be calculated outside the summation because it is not dependent on $D$. The summation portion of the expression is precalculated based on $\Lambda_{r}$ values at $1 \mathrm{~m}^{-1}$ increments from 0.0 to $30000.0 \mathrm{~m}^{-1}$, which for simplicity will be referred to as $S\left(\Lambda_{r}\right)$. During assimilation, $\Lambda_{r}$ is calculated based on the model predicted $q_{r}$ and $N_{\mathrm{tr}}$. The corresponding $S\left(\Lambda_{r}\right)$ value can be quickly looked up from the precalculated table since the increment range of $\Lambda_{r}$ is known. If the model calculated $\Lambda_{r}$ value is between two $\Lambda_{r}$ values in the table, the associated $S\left(\Lambda_{r}\right)$ values are interpolated. Precalculated lookup tables for this part of the expression are computed for all hydrometeor categories and all possible water fractions as detailed in Jung et al. (2010a) for their Eqs. (3) (for $Z_{h}$ ) and (4) (for $Z_{v}$ ). The individual linear $Z$ values are added together to calculate the logarithmic $Z_{H}$ and $Z_{V}$ using Eqs. (14) and (15) from Jung et al. (2008a) and $Z_{\mathrm{DR}}$ is calculated from the ratio of $Z_{H}$ and $Z_{V}$ using their
Eq. (16). Although there are some small differences in the calculated variables using the modified operator compared to the Jung et al. (2010a) operators, which are on the order of $10^{-2}$ for both $Z(\mathrm{~dB} Z)$ and $Z_{\mathrm{DR}}(\mathrm{dB})$, the improvement in the calculated variables using these operators compared to using the Jung et al. (2008a) operators is quite important.

\section{Results of EnKF analyses}

The experiment includes a 30-min evaluation window in the later part of the assimilation period, from 1930 to 2000 UTC, where results are compared to observations. During this window, the main storm of interest, the Newcastle-Moore tornadic supercell, and another supercell immediately to its north over Oklahoma City (see Fig. 1), were maturing and moving within close vicinity to KTLX, allowing for an assessment using observations as close to the surface as possible (where polarimetric signatures due to size sorting are most prominent). For convenience, we will refer to these storms as the "Moore" and "OKC" storms, respectively. The OKC storm is included in the evaluation due to its close proximity to the Moore storm, leading to continuous precipitation between their forward flanks. The gray box in Fig. 1 highlights a subdomain focused on the Moore and OKC storms that will be used for evaluation.

A detailed evaluation will be performed for analyses at 1940 UTC. This evaluation time is chosen because it is a time when the Moore storm is closest to KTLX before the forward flank of the supercell begins to pass over the KTLX cone of silence at the $0.5^{\circ}$ tilt. The cone of silence is the region above the highest radar tilt where observations are missing and is illustrated with a cross section of KTLX observations through the Moore storm at 1938 UTC in Fig. 4. The cross section shows that a large portion of the storm above the surface is already within the cone of silence, noted by the shaded gray region with "no data," and this is the final volume scan before the lowest observations available for assessment are also interrupted. An RMSI plot for both $Z$ and $Z_{\mathrm{DR}}$ over the entire evaluation period from 1930 to 2000 UTC is given in Fig. 5; it includes calculations for both the $0.5^{\circ}$ tilt of KTLX as well as for all observations below $2000 \mathrm{~m}$ where $Z_{\mathrm{DR}}$ is assimilated. The analyses for 1940 UTC have RMSIs within the range of the previous two assimilation times and lower than future assimilation times, when the storm begins to pass over KTLX.

Figures 6-8 contain the ensemble mean analyses of $Z$ and $Z_{\mathrm{DR}}$ from EXPZ and EXPZZDR at 1930, 1935, and 1940 UTC, as well as the respective closest-in-time KTLX observations on the $0.5^{\circ}$ tilt, which represent the 


\section{Cross-section}

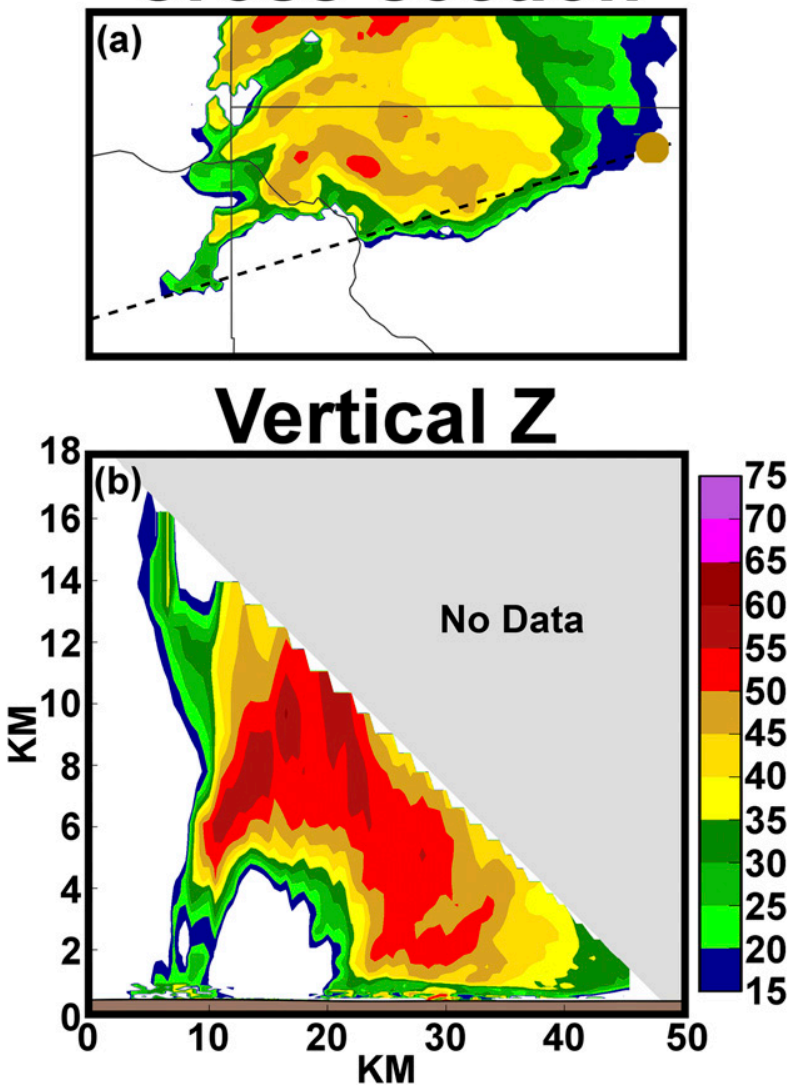

FIG. 4. (a) Horizontal plot of reflectivity at the $0.5^{\circ}$ tilt of KTLX at 1938 UTC and (b) vertical cross section of reflectivity from KTLX at 1938 UTC along the black dashed line indicated in (a). The brown circle in (a) denotes the location of KTLX. The gray region in (b) notes where no data are present in the cone of silence.

three analysis times before the storm passes over KTLX. Both the observations and model results are interpolated to the same model grid columns horizontally and elevation levels of KTLX vertically. The $Z_{\mathrm{DR}}$ plots for EXPZ and EXPZZDR show similar notable differences in the magnitude and patterns of $Z_{\mathrm{DR}}$ values at all three times. Specifically, the $Z_{\mathrm{DR}}$ values for the Moore storm in EXPZZDR are higher than EXPZ along the southern portion of the forward flank and lower to the north downshear in the forward flank when compared to the observations. Thus, the results at 1940 UTC are representative of the other earlier times within the evaluation period before the cone of silence interferes with the lowlevel observations of $Z_{\mathrm{DR}}$ that are assimilated.

\section{a. Evaluation of analyzed polarimetric variables}

In this section we perform a detailed analysis of the results from 1940 UTC (Fig. 8). Analyzed $Z$ is generally similar between EXPZ and EXPZZDR. In the OKC storm, the greatest difference between the experiments is that $Z$ is overestimated in the forward flank to a greater extent in EXPZ compared to EXPZZDR. Analyzed $Z$ in the southeastern portion of the forward flank of the Moore storm is underestimated in both experiments. Ensemble underdispersion is higher in this area, but earlier sensitivity experiments conducted for this study using different observation errors and model error treatment methods [e.g., multiplicative inflation (Anderson 2001) and additive perturbations (Dowell and Wicker 2009)] did not improve the analysis of these regions in any meaningful manner (not shown). The low $Z$ bias in the model results has been noted in past studies using the MY2 scheme (Dawson et al. 2010; Morrison and Milbrandt 2011; Dawson et al. 2015). Dawson et al. (2010) attributed this to excessive size sorting known to occur with the MY2 scheme (Milbrandt and Yau 2005a). Larger drops fall in close proximity to the updraft while smaller drops are then advected northwestward by the low-level storm-relative winds, which are approximately southeasterly at this time, leading to underestimated precipitation in the southern portion of the forward flank [cf. Figs. $4 \mathrm{c}$ and $4 \mathrm{~d}$ of Dawson et al. (2015) and Figs. 6d and 6f of Dawson et al. (2010)].

The impact of assimilated $Z_{\mathrm{DR}}$ is most noticeable in the Moore storm. The analyzed $Z_{\mathrm{DR}}$ values in EXPZZDR for the Moore storm are higher than EXPZ near the location of the observed $Z_{\mathrm{DR}}$ arc and lower immediately to the north (Figs. 8b,d,f). Together, these patterns are indicative of the size sorting processes associated with the deep-layer storm-relative wind shear that lead to the larger drops adjacent to the updraft while smaller drops are advected farther downshear (Dawson et al. 2014). It should be noted, however, that the orientation of the higher $Z_{\mathrm{DR}}$ values in EXPZZDR is displaced to the north compared to the observed $Z_{\mathrm{DR}}$ arc and that the values are underestimated overall, perhaps again indicative of excessive size sorting in the MY DM scheme. The $Z_{\mathrm{DR}}$ arc has also been noted in a previous supercell simulation study to be located farther within the forward flank and have a smaller gradient along the edge of the precipitation than typically observed (Johnson et al. 2016).

The difference, or innovation, between the observations and the analyzed $Z$ and $Z_{\mathrm{DR}}$ for EXPZ and EXPZZDR on the same $0.5^{\circ}$ KTLX elevation as in Fig. 8 is plotted in Fig. 9. The observations from the KTLX $0.5^{\circ}$ scan at 1938 UTC are included for reference. Areas of warm, orange colors indicate where the observed values are higher than the analyzed value and cool, blue colors indicate where the observed values are lower than the analysis. Overall, $Z$ innovation is similar in the two experiments. The underestimated $Z$ in the 

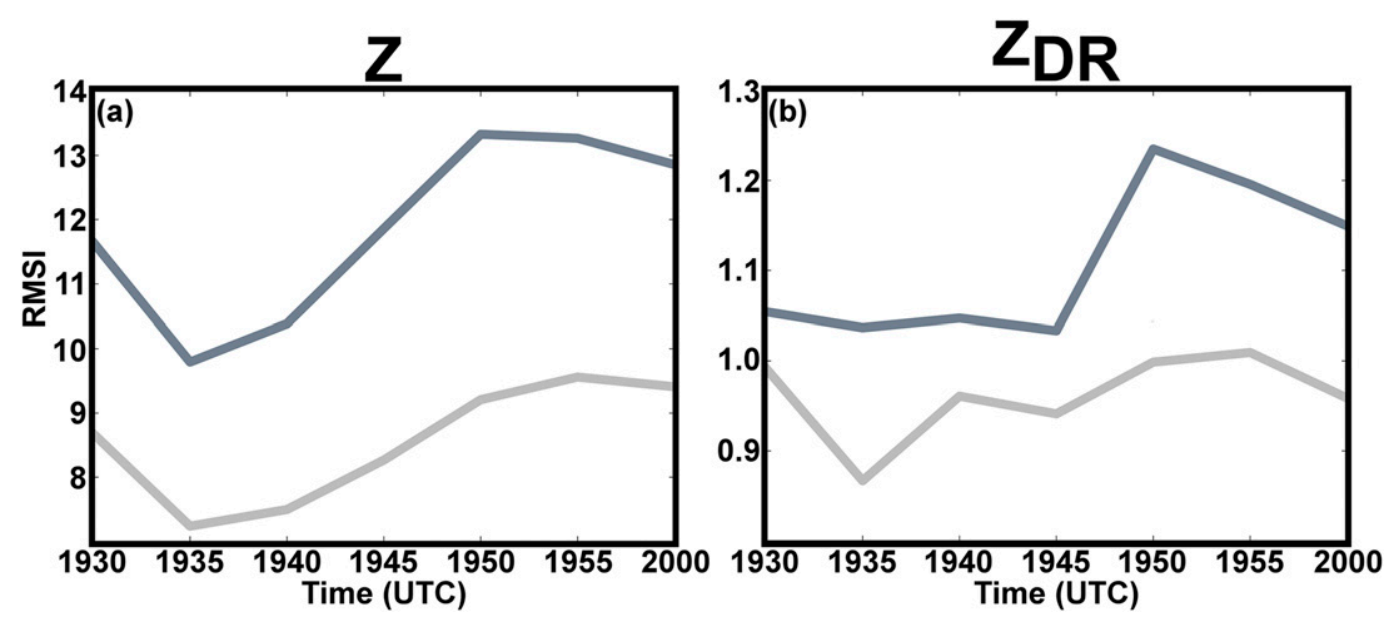

FIG. 5. Root-mean-square innovations (RMSIs) for posterior (a) $Z$ and (b) $Z_{\mathrm{DR}}$ for the evaluation period (19302000 UTC). Calculations are done over the evaluation domain given in Fig. 1 . The light gray line is for the $0.5^{\circ}$ tilt of KTLX and the dark gray line is for all observations below $2000 \mathrm{~m}$.

southeastern portion of the forward flank for both storms noted in Fig. 8 is easily identified by the dark orange colors in Figs. 9c,e. The $Z_{\mathrm{DR}}$ plots highlight greater differences between the two experiments. For the Moore storm, the difference between analyzed and observed $Z_{\mathrm{DR}}$ for EXPZZDR is smaller compared to that in EXPZ (Figs. 9b,d,f). Analyzed $Z_{\mathrm{DR}}$ values are overestimated by a greater amount in the central and eastern portions of the forward flank of the Moore storm in EXPZ compared to EXPZZDR. Analyzed $Z_{\mathrm{DR}}$ values in EXPZ are underestimated by a greater amount in the southern portion of the forward flank, where the
KTLX OBS
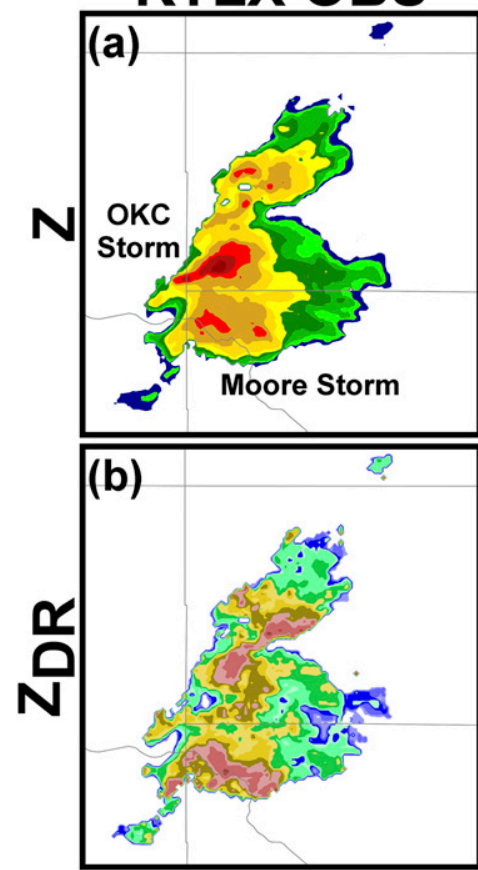

EXPZ
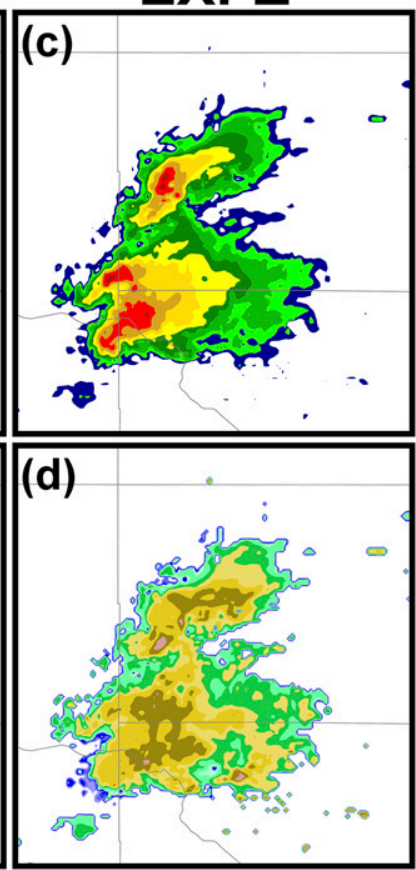

EXPZZDR
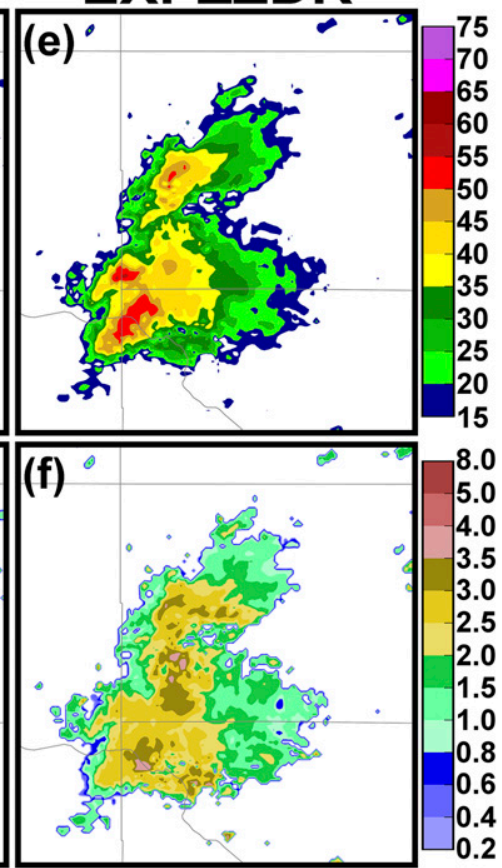

FIG. 6. (a) Reflectivity (dBZ) and (b) differential reflectivity (dB) from KTLX at 1929 UTC as well as from the corresponding ensemble mean analyses at 1930 UTC from (c),(d) EXPZ and (e),(f) EXPZZDR interpolated horizontally to the model grid columns and vertically to the $0.5^{\circ}$ elevation of KTLX for the evaluation domain given in Fig. 1. The locations of the "OKC" and "Moore" storms are noted in (a). 


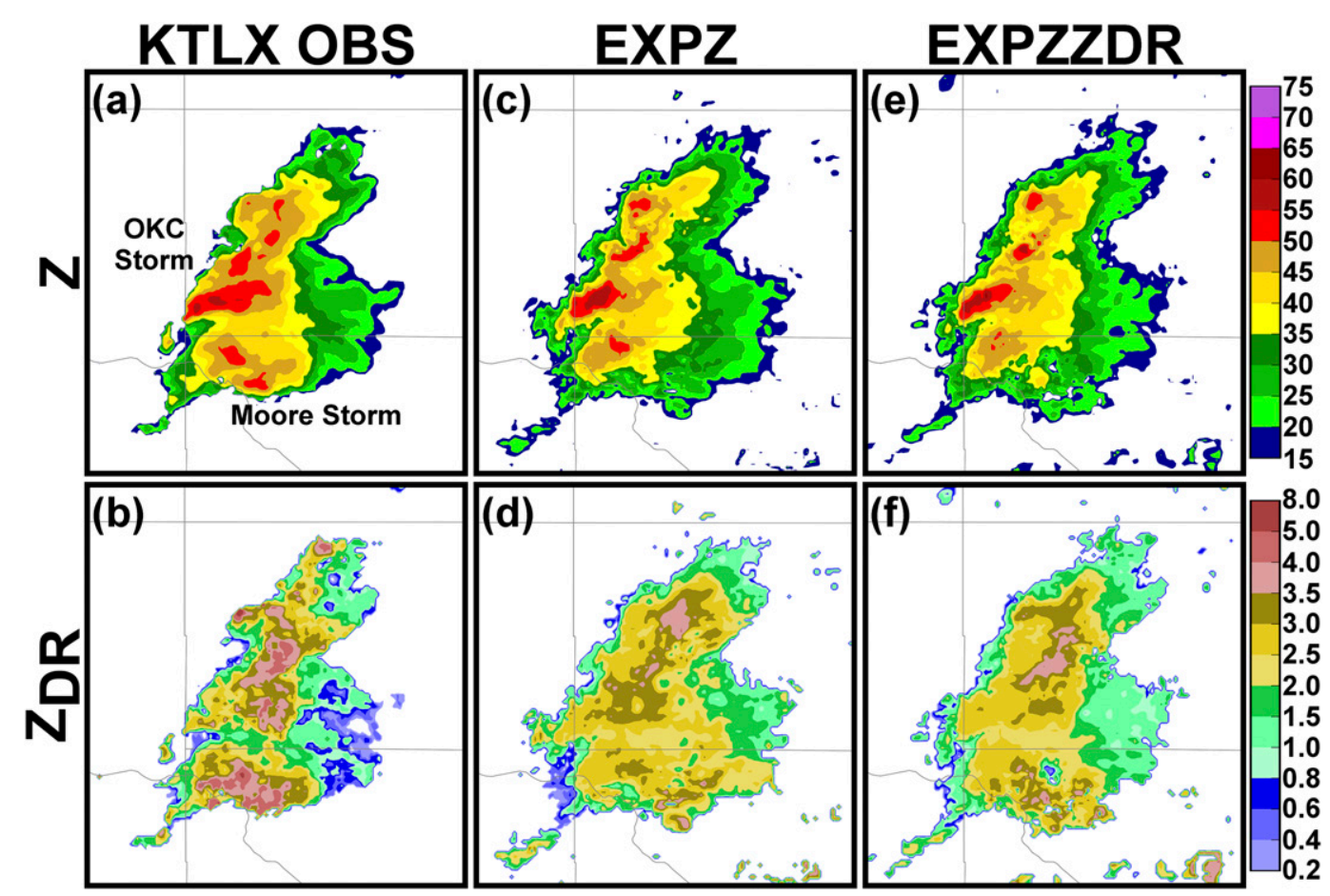

FIG. 7. As in Fig. 6, but for the analysis at 1935 UTC and KTLX observations from 1934 UTC.

observed $Z_{\mathrm{DR}}$ arc exists, compared to EXPZZDR. Therefore, analysis errors of $Z_{\mathrm{DR}}$ are larger in EXPZ than in EXPZZDR, although significant differences still exist (as large as $6 \mathrm{~dB}$ ) between EXPZZDR and the observations.

It is notable that the patterns of analyzed $Z$ are more similar between the experiments as compared to those of $Z_{\mathrm{DR}}$. Ultimately, the goal of assimilating polarimetric observations is to provide an improved estimate of the model microphysical states. The $Z_{\mathrm{DR}}$ analysis in EXPZZDR is improved over EXPZ compared to observations, while $Z$ in EXPZZDR is more similar to that of EXPZ compared to the observations, suggesting that EXPZZDR better represents the observed microphysical states. In other words, when $Z$ alone is assimilated, there are multiple possible combinations of microphysical states (mixing ratios and total number concentrations in our case) that can fit the values of $Z$, many of which have substantial errors compared to the true microphysical states. The assimilation of $Z_{\mathrm{DR}}$ provides additional information and constraint on the microphysical states by narrowing the range of possible microphysical states that can fit the assimilated observations and leading to better state estimation. Analyzing $Z$ alone may provide a good fit to observations in terms of reflectivity coverage and intensity, but the estimate of individual microphysical states may still contain significant error.
$Z_{\mathrm{DR}}$ values are only assimilated at heights of $2 \mathrm{~km}$ AGL or below, but observed information can be spread to other regions of model domain via covariance structures in the EnKF. Vertical cross sections of $Z_{\mathrm{DR}}$ from observations and analysis results are plotted in Fig. 10 to illustrate the impact of assimilating $Z_{\mathrm{DR}}$ values below $2 \mathrm{~km}$ AGL on regions above. The diagonal black dashed lines in the top panels of Fig. 10 indicate the location of the vertical cross sections plotted in the bottom panels while the black contours in Figs. 10d, f indicate the freezing level and the purple contours indicate the strength of the vertical updraft ( $w$, in $15 \mathrm{~m} \mathrm{~s}^{-1}$ contours). The cross section is oriented to intersect both the rear flank downdraft and forward flank region so that both the main updraft and the $Z_{\mathrm{DR}}$ column are included, similar to Fig. 6 of Kumjian and Ryzhkov (2008). The $Z_{\mathrm{DR}}$ column is a region of increased $Z_{\mathrm{DR}}$ near and within the updraft caused by vertical advection of oblate raindrops by the updraft. These raindrops, which remain liquid due to a positive temperature perturbation and insufficient time to freeze in the updraft, exhibit much higher $Z_{\mathrm{DR}}$ than the frozen hydrometeors at the same level in the surrounding portions of the storm. The increase in $Z_{\mathrm{DR}}$ can also be due to melting hailstones. The observed $Z_{\mathrm{DR}}$ column can be noted in Fig. 10b (at $x \sim 15 \mathrm{~km}$ ) by the presence of $Z_{\mathrm{DR}}$ values exceeding $2 \mathrm{~dB}$ well above $2000 \mathrm{~m}$ while the significant decrease in $Z_{\mathrm{DR}}$ above this height elsewhere in the 


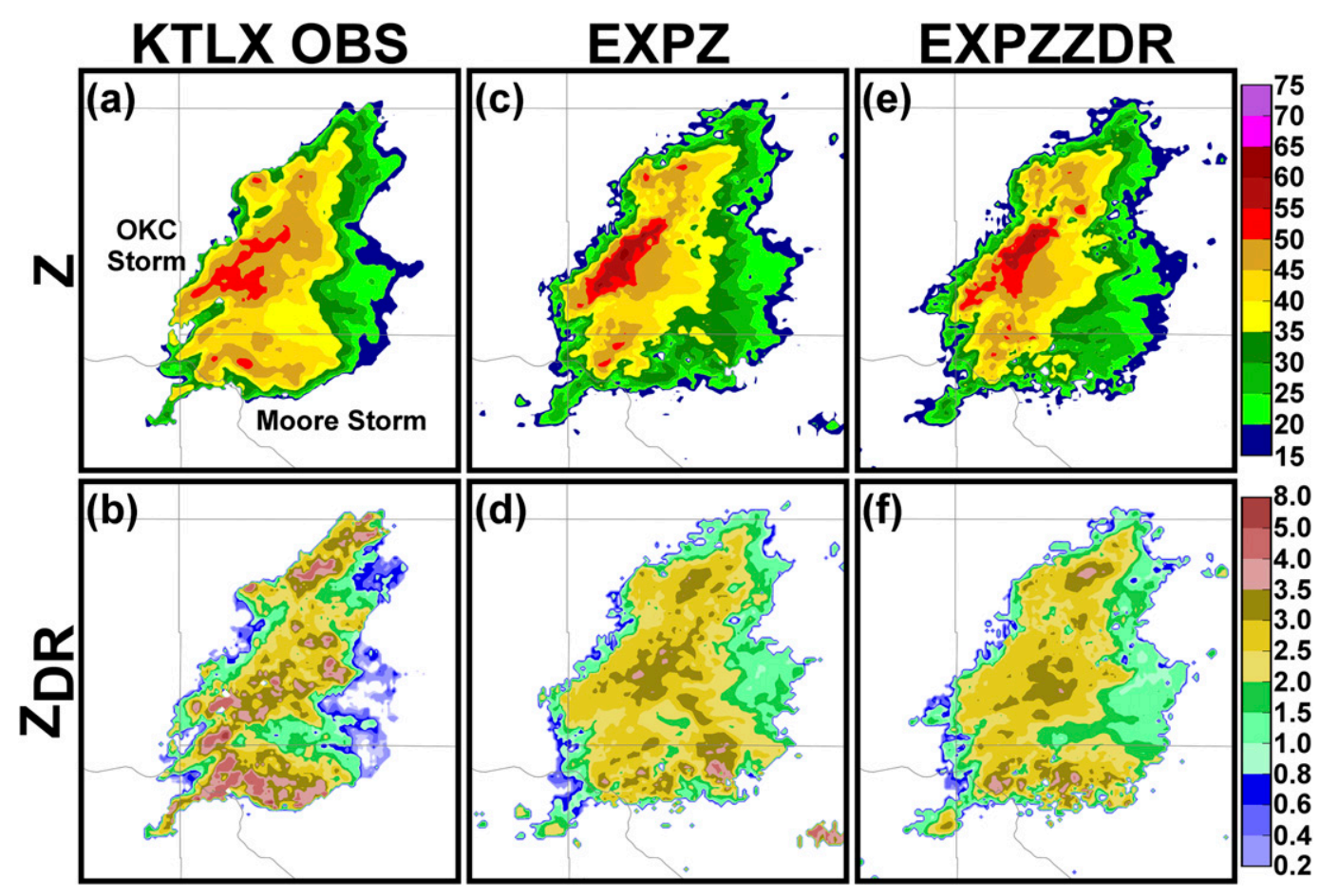

FIG. 8. As in Fig. 6, but for the analysis at 1940 UTC and KTLX observations from 1938 UTC.

cross section suggests the presence of the environmental freezing level.

$Z_{\mathrm{DR}}$ values near the surface in EXPZZDR are higher where the vertical cross section bisects the $Z_{\mathrm{DR}}$ arc and lower farther downshear in the forward flank downdraft compared to EXPZ and more similar to the observations (Figs. $10 \mathrm{~b}, \mathrm{~d}, \mathrm{f}$ ). There is a column of higher $Z_{\mathrm{DR}}$ values (of above $3 \mathrm{~dB}$ ) in EXPZZDR from the surface to $4 \mathrm{~km}$ (Fig. 10f, at $x \sim 20 \mathrm{~km}$ ) above the $Z_{\mathrm{DR}}$ arc region compared to EXPZ (Fig. 10d). In fact, the vertical distribution of $Z_{\mathrm{DR}}$ values of approximately $3 \mathrm{~dB}$ in this region in EXPZZDR are similar to the observations, although the values are underestimated and their locations are displaced by about $4 \mathrm{~km}$ to the northeast. Additionally, in EXPZZDR, there is a small vertical column of $Z_{\mathrm{DR}}$ values of around $1 \mathrm{~dB}$ that extends up to the height of the $Z_{\mathrm{DR}}$ column in the observations (Fig. 10f, at $x \sim 13 \mathrm{~km}$ ), collocated with the local maximum $w$ in the model updraft, which is also stronger compared to EXPZ. Although the vertical distribution of $Z_{\mathrm{DR}}$ values in EXPZZDR better reflects the observations than that of EXPZ (Figs. 10b,d,f), these values are underestimated and not as widely distributed as the observed $Z_{\mathrm{DR}}$ column above the freezing level (Fig. 10b, at $x \sim 15 \mathrm{~km}$ ) nor as narrow as the observed values below the freezing level. This may be partially due to the low amount of hail in this region; melting hailstones can increase the $Z_{\mathrm{DR}}$ values in the column. Also, the low
$Z_{\mathrm{DR}}$ column depth is mainly due to fast liquid to ice conversion seen with the MY scheme, which underestimates liquid water content in the updraft region (Johnson et al. 2016). Assimilation of $Z_{\mathrm{DR}}$ values above the freezing level, specifically in regions associated with the $Z_{\mathrm{DR}}$ column, may improve analyses of $Z_{\mathrm{DR}}$; currently, large uncertainties with the observation operator and associated microphysics at the freezing/melting level prevents us from doing so, as discussed earlier, but it will be explored in future research.

Analyzed $V_{r}$ also shows a better fit to the observations in EXPZZDR compared to EXPZ. Specifically, the strength of the midlevel mesocyclone of the Moore storm is significantly improved in EXPZZDR. Observed $V_{r}$ at 1938 UTC and analyzed $V_{r}$ for EXPZ and EXPZZDR at 1940 UTC at the $8.06^{\circ}$ tilt from KTLX are plotted in Fig. 11. The observed midlevel mesocyclone is noted by the black circle and is at approximately $5 \mathrm{~km}$ AGL. There are notable outbound velocities of similar magnitude to indicate the location of the midlevel mesocyclone in the observations and EXPZZDR, while this feature is missing in EXPZ. Several observational studies have shown a positive correlation between increased values of $Z_{\mathrm{DR}}$ in the $Z_{\mathrm{DR}}$ column and the strength of the updraft (e.g., Hubbert et al. 1998; Kumjian et al. 2014; Snyder et al. 2015). Additionally, Carlin et al. (2017) showed assimilating $Z_{\mathrm{DR}}$ column information, in terms of positive temperature and moisture perturbations, led 
KTLX OBS
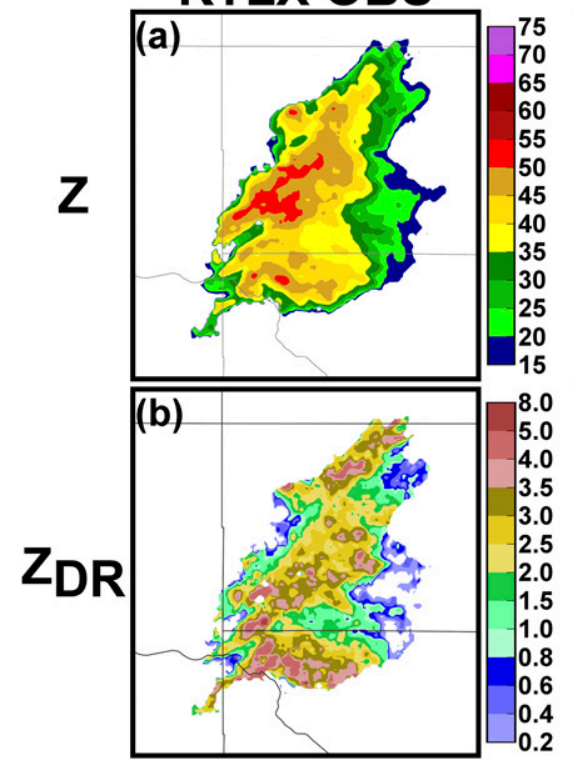

EXPZ

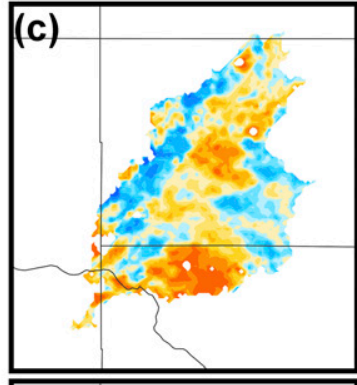

(d)

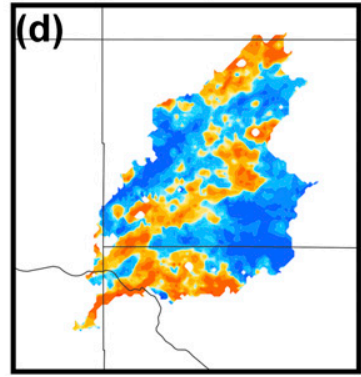

EXPZZDR

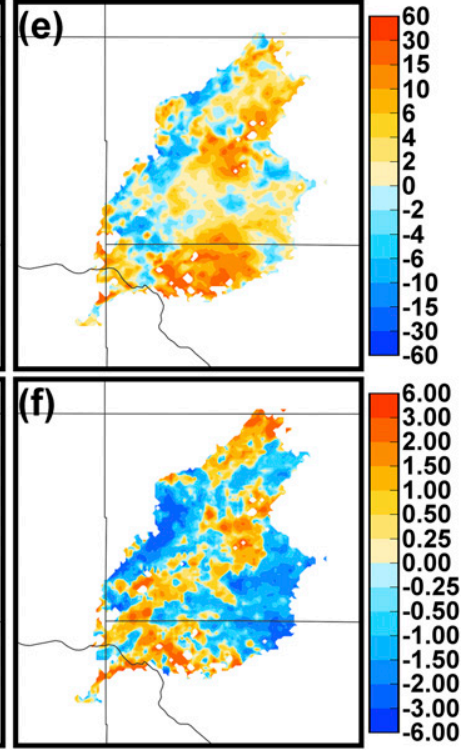

FIG. 9. (a) Reflectivity (dBZ) and (b) differential reflectivity (dB) from KTLX at 1938 UTC, (c) reflectivity observation minus ensemble mean analysis and (d) differential reflectivity observation minus analysis for EXPZ, and (e),(f) corresponding difference fields for EXPZZDR at $1940 \mathrm{UTC}$ at the $0.5^{\circ}$ elevation of KTLX as in Fig. 8.

to improved updraft helicity tracks (Carlin et al. 2017). In our case, the higher $Z_{\mathrm{DR}}$ values in the vicinity of the updraft of EXPZZDR noted above and the increased $V_{r}$ values in the midlevel mesocyclone show a positive correlation between assimilating $Z_{\mathrm{DR}}$ and the strength of the midlevel mesocyclone.

\section{b. Evaluation of estimated microphysical states}

\section{1) ESTIMATE OF MODEL MICROPHYSICAL STATES AT THE SURFACE}

In this section, the impact of assimilating $Z_{\mathrm{DR}}$ on the estimate of model microphysical states is further investigated by examining variables related to the hydrometeor PSDs. The rainwater mean mass diameter $\left(D_{\mathrm{nr}}\right.$, in $\mathrm{mm})$ and total raindrop number concentration $\left(N_{\mathrm{tr}}\right.$, in number per meter cubed) at the first model level above the surface (approximately $50 \mathrm{~m}$ AGL) in the analyses are compared to retrieved values from the KTLX radar observations (Fig. 12) (note that given $D_{\mathrm{nr}}$ and $N_{\mathrm{tr}}$, the exponential rain DSD and the rainwater mixing ratio can be uniquely determined). Both storms are located very close to the KTLX radar, and thus $0.5^{\circ} \mathrm{KTLX}$ observations are quite close to the surface, with a mean height of $200 \mathrm{~m}$, making them suitable for comparison with the analyzed fields near the surface. The retrieved values are obtained using a direct retrieval method (Zhang 2016, his section 6.4.3) based on the constrainedgamma (C-G) rain drop size distribution (DSD) model
(Zhang 2015). The $D_{\mathrm{nr}}$ and rainwater content ( $W$, in $\mathrm{g} \mathrm{m}^{-3}$ ) are expressed in terms of observed $Z_{h}$ and $Z_{\mathrm{DR}}$ as:

$$
\begin{aligned}
D_{\mathrm{nr}}= & 0.0657 \times Z_{\mathrm{DR}}^{3}-0.332 \times Z_{\mathrm{DR}}^{2} \\
& +1.090 \times Z_{\mathrm{DR}}+0.689
\end{aligned}
$$

and

$$
\begin{aligned}
W= & 1.023 \times 10^{-3} \times Z_{h} \\
& \times 10^{-0.0742 \times Z_{\mathrm{DR}}^{3}+0.511 \times Z_{\mathrm{DR}}^{2}-1.511 \times Z_{\mathrm{DR}},}
\end{aligned}
$$

where $Z_{h}$ is in linear units $\left(\mathrm{mm}^{6} \mathrm{~m}^{-3}\right)$ and $Z_{\mathrm{DR}}$ is in $\mathrm{dB}$; $W$ can then be used to calculate $N_{\text {tr }}$ :

$$
N_{\mathrm{tr}}=\frac{W}{\pi} \times 10^{3} \times\left(\frac{4}{D_{\mathrm{nr}}}\right)^{3} .
$$

The $Z_{\mathrm{DR}}$ observations used in the retrieval are capped at $4.5 \mathrm{~dB}$ because simulated $Z_{\mathrm{DR}}$ values calculated using the $\mathrm{C}-\mathrm{G}$ model rarely exceed this value. Additionally, $D_{\mathrm{nr}}$ and $N_{\mathrm{tr}}$ values are only retrieved in areas that are identified as one of the rain-only categories (rain, large raindrops, or heavy rain) by the Park et al. (2009) HCA (Fig. 12). Both of these steps will mainly avoid retrieval of $D_{\mathrm{nr}}$ and $N_{\mathrm{tr}}$ in areas with melting hail.

The retrieved $D_{\mathrm{nr}}$ and $N_{\mathrm{tr}}$ values (Figs. 12a,b) are higher compared to those predicted in the model (Figs. 12c,d,e,f), suggesting that the microphysics scheme and/or the DA procedure underestimates 


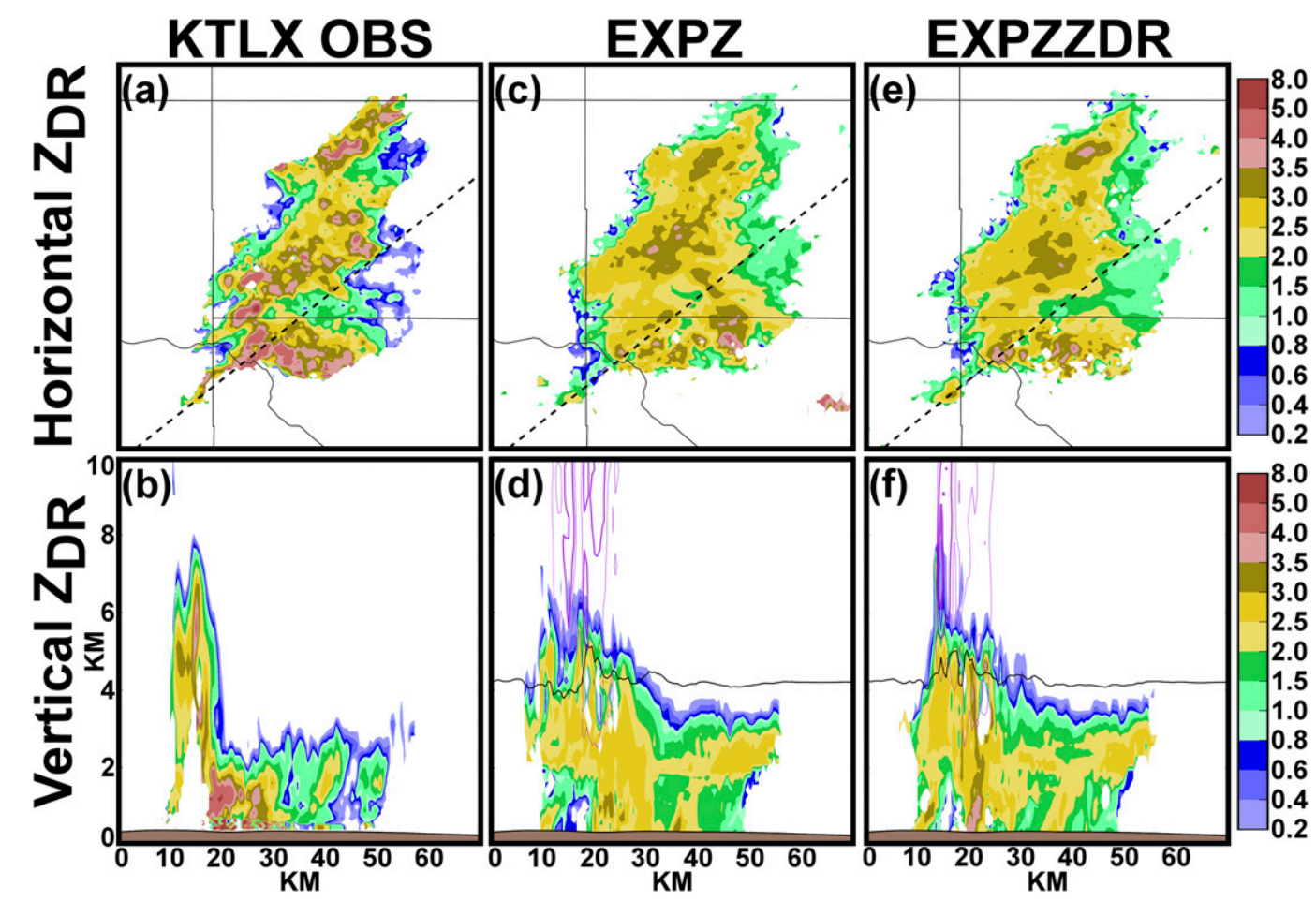

FIG. 10. (a) Differential reflectivity (dB) at the $0.5^{\circ}$ tilt from KTLX at 1938 UTC and (b) a vertical cross section of differential reflectivity from KTLX for the same volume scan as (a), and corresponding fields from the ensemble mean analysis at 1940 UTC for (c),(d) EXPZ and (e),(f) EXPZZDR. The location of the vertical cross sections is noted by the black dashed line in (a),(c),(e). The model freezing level is indicated by the black line in (d),(f). Positive values of vertical velocity $\left(\mathrm{m} \mathrm{s}^{-1}\right)$ are indicated by the purple contours in (d),(f).

mean mass raindrop size and the total number of drops compared to the observations. However, caution must be taken in interpreting the numerical values of retrieved $D_{\mathrm{nr}}$ and $N_{\mathrm{tr}}$ compared to the model results. For example, the retrieval method assumes a nonzero DSD shape parameter $\alpha$, while the rain DSD used in the Mibrandt and Yau DM scheme assumes a zero value of $\alpha$ and an exponential DSD. Differences in this case, however, can be attributed to model error and qualitative agreement can be viewed as improvement; more general TM MP schemes may be explored in the future. Additionally, the retrieval equations were derived based on relations between rain DSD parameters and radar measurements, which may contain errors. However, previous studies have shown retrieval results to be reasonable when compared to independent disdrometer data (Brandes et al. 2003; Cao et al. 2008; Fig. 6.17 of Zhang 2016). Thus, a qualitative comparison with observation-based retrievals is sought here while the quantitative differences should be viewed with the noted caveats in mind.

The pattern of $D_{\mathrm{nr}}$ in EXPZZDR (Fig. 12e) better reflects the distribution of the observed $Z_{\mathrm{DR}}$ pattern from Fig. $8 \mathrm{~b}$ compared to that of EXPZ (Fig. 12c). It is expected that the rain DSDs that produce high $Z_{\mathrm{DR}}$ values will also have high mean mass diameter values (and vice versa for low $Z_{\mathrm{DR}}$ values), and this is seen in the $D_{\mathrm{nr}}$ field of EXPZZDR, particularly where high $D_{\mathrm{nr}}$ values (Fig. 12e) are collocated with the $Z_{\mathrm{DR}}$ arc of the Moore storm in the observations (Fig. 8b). Additionally, $D_{\mathrm{nr}}$ values are lower farther downshear in the forward flank of EXPZZDR away from the local maximum in the $Z_{\mathrm{DR}}$ arc. Differences between $D_{\mathrm{nr}}$ in EXPZ and EXPZZDR indicate that the improvement in the analyzed $Z_{\mathrm{DR}}$ patterns in EXPZZDR discussed in section $4 \mathrm{a}$ is reflected in a corresponding improved estimate of the model microphysical states related to the rain DSD.

The retrieved and analyzed $N_{\mathrm{tr}}$ values are plotted in the bottom panels of Fig. 12. High $Z_{\mathrm{DR}}$ values are found to be associated with DSDs with lower $N_{\mathrm{tr}}$ values, representing distributions with long tail ends (i.e., a few, larger drops), while low $Z_{\mathrm{DR}}$ values are found to be associated with DSDs with higher $N_{\text {tr }}$ values (i.e., a very high number of smaller drops) (Cao et al. 2008). In the evaluation of $Z_{\mathrm{DR}}$ in section 4a, a local minimum in $Z_{\mathrm{DR}}$ was noted in the observations and in EXPZZDR between the higher values associated with the $Z_{\mathrm{DR}}$ arcs in the Moore and OKC storms (Figs. 8b,f). In this region, 
KTLX OBS

(a)

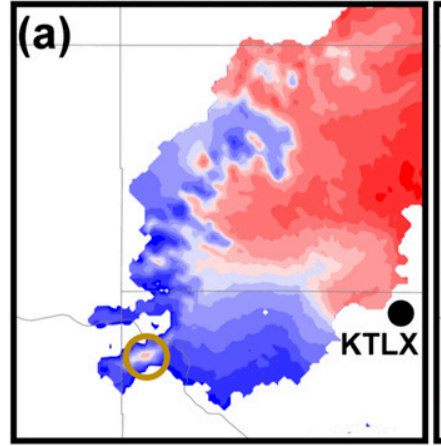

EXPZ

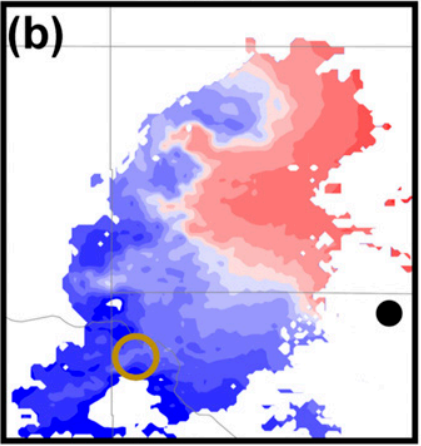

EXPZZDR

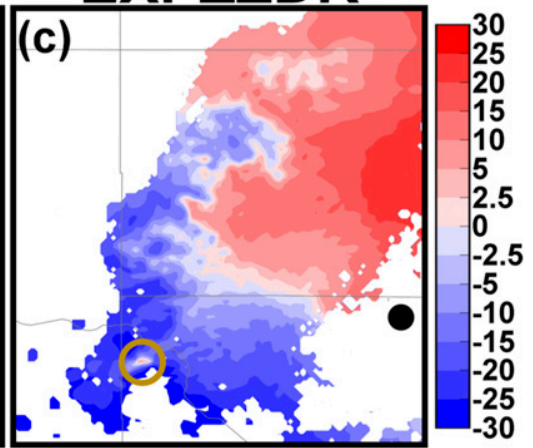

FIG. 11. (a) Observed radial velocity $\left(V_{r}\right)$ at the $8.06^{\circ}$ tilt of KTLX (location noted by the black circle) at 1938 UTC as well as analyzed $V_{r}$ for (b) EXPZ and (c) EXPZZDR at 1940 UTC at the same tilt. The golden circle indicates the location of the midlevel mesocyclone for the Moore storm.

the $N_{\text {tr }}$ values in EXPZZDR (Fig. 12f) are higher than those in EXPZ (Fig. 12d), indicating a higher number of raindrops (specifically of small drops) present in the model, which is expected given the low observed $Z_{\mathrm{DR}}$ values in the region (Fig. 8b). These higher values of $N_{\text {tr }}$ also extend farther downshear in the forward flank in EXPZZDR than in EXPZ for both the Moore and OKC storms. The retrieved $N_{\text {tr }}$ values are higher than the analyzed values, but the spatial pattern in EXPZZDR better matches that of the observation retrieval. More detailed investigations of retrieved $D_{\mathrm{nr}}$ and $N_{\mathrm{tr}}$, perhaps with more suitable assumptions on the DSDs, are needed and are a topic for future study, but these initial results indicate an encouraging improvement in the overall patterns of analyzed microphysical fields in EXPZZDR compared to those in EXPZ. It should be noted that we also investigated other model state variables, including the surface temperature to gauge the strength of the surface cold pool; no significant difference was found in the strength of the cold pool.

\section{2) ESTIMATE OF MODEL MICROPHYSICAL STATES ABOVE THE SURFACE}

As discussed in section 1, the covariance structures in the EnKF can spread observed information above $2 \mathrm{~km}$ AGL where $Z_{\mathrm{DR}}$ observations are not assimilated. The rainwater mixing ratio $\left(q_{r}\right.$, in $\left.\mathrm{g} \mathrm{m}^{-3}\right)$ and $D_{\mathrm{nr}}$ are plotted in Fig. 13 at $2 \mathrm{~km}$ AGL. The hail mixing ratio $\left(q_{h}\right)$ is plotted along with the mean mass diameter of hail $\left(D_{\mathrm{nh}}\right)$ at $4 \mathrm{~km}$ AGL in Fig. 14 and at $6 \mathrm{~km}$ AGL in Fig. 15. The difference between the two experiments (EXPZZDREXPZ) for the relevant fields is also plotted in Figs. 1315. The green dot marks the location of the updraft based on a local maximum in vertical velocity. The impact of assimilating $Z_{\mathrm{DR}}$ on hail-related fields is important considering that $Z_{\mathrm{DR}}$ values are assimilated only below the melting layer and that $Z_{\mathrm{DR}}$ values are typically near $0.0 \mathrm{~dB}$ for frozen hydrometeors (see Fig. 10b). In other words, any impact of the $Z_{\mathrm{DR}}$ assimilation on hail will have to come directly through ensemble covariances and model state interactions in the modeling integration during the DA cycles.

Substantial differences in $q_{r}$ (Fig. 13e) between EXPZ and EXPZZDR are mainly confined to regions close to the updraft in the forward flank of the Moore and OKC storms. In particular, there is a notable reduction in the water content in the forward flank of the OKC storm in EXPZZDR compared to EXPZ, which corresponds to the improvement seen in the $Z$ fields of EXPZZDR (Fig. 8e) compared to the observations near the surface relative to EXPZ (which overestimates $Z$ ). There is only a small increase in $D_{\mathrm{nr}}$ along the right-forward flank of the Moore storm in EXPZZDR, which is not surprising considering that $Z_{\mathrm{DR}}$ within the $Z_{\mathrm{DR}}$ arc is highest at the surface (where the most size sorting has occurred). Assimilation of $Z_{\mathrm{DR}}$ appears to have a small but expected impact on the rain DSDs at $2 \mathrm{~km}$ in EXPZZDR, despite this being the upper limit of the vertical extent where $Z_{\mathrm{DR}}$ is assimilated.

A more substantial difference is seen between the two experiments in the hail fields at $4 \mathrm{~km}$ (Fig. 14) and $6 \mathrm{~km}$ AGL (Fig. 15). There is an increase in $q_{h}$ adjacent to the updraft in the Moore storm in EXPZZDR. Additionally, there is an increase in $D_{\mathrm{nh}}$ at this same location at both 4 and $6 \mathrm{~km}$ in EXPZZDR, while there is a decrease in $D_{\text {nh }}$ farther away from the updraft along the rightforward flank. This can be seen more clearly in the difference fields (Figs. 14f and 15f). The negative gradient of $D_{\mathrm{nh}}$ downshear, relative to the storm motion, from the updraft in the right-forward flank of the Moore storm in EXPZZDR matches the distribution of $D_{\text {nh }}$ presented in the schematic in Fig. 17 of Dawson et al. (2014). 


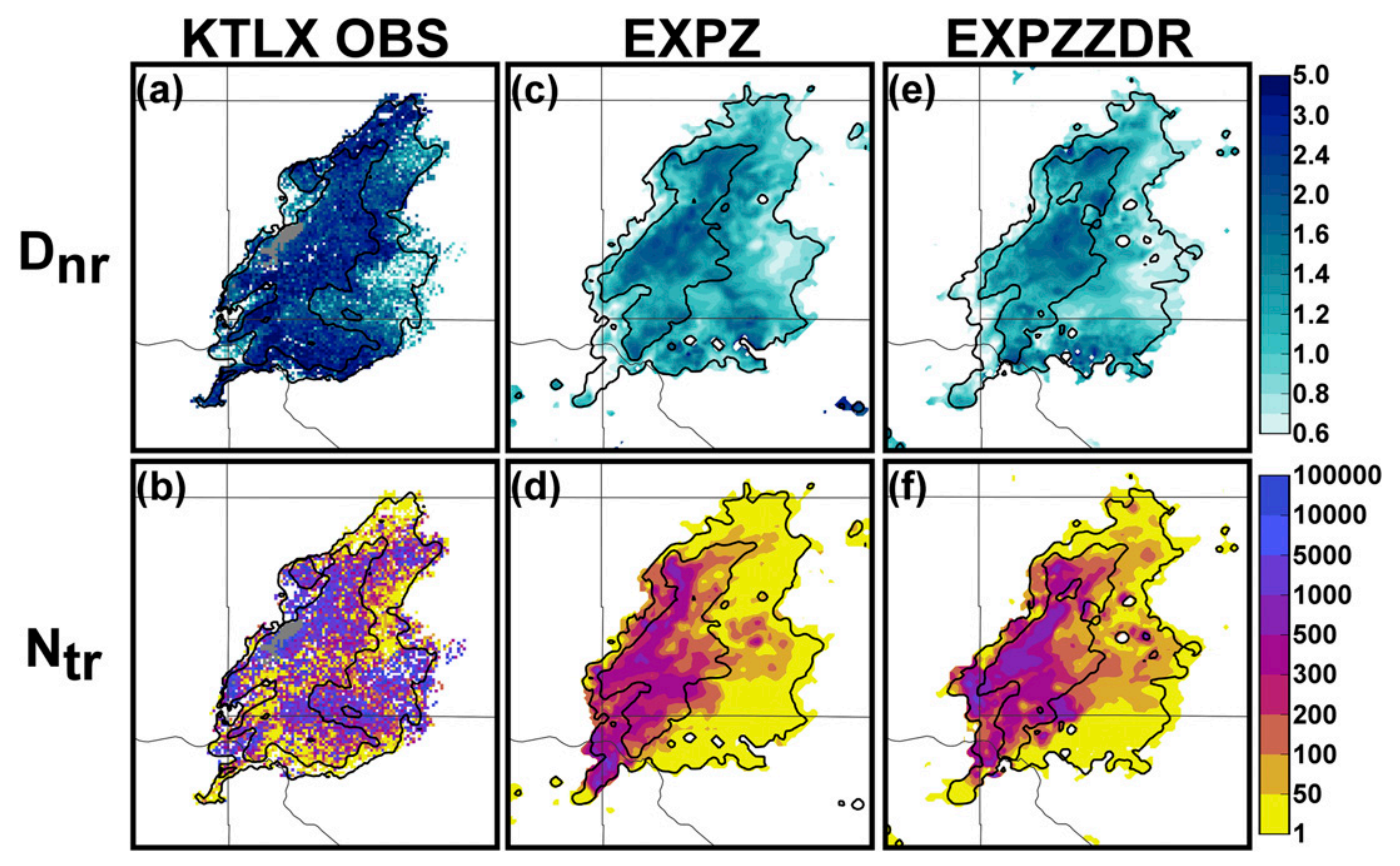

FIG. 12. (a) Rain mean mass diameter $\left(D_{\mathrm{nr}}\right.$, in $\left.\mathrm{mm}\right)$ and (b) total number concentration $\left(N_{\mathrm{tr}}\right.$, in number per meter cubed) retrieved from KTLX radar observations at 1938 UTC at the $0.5^{\circ}$ tilt, and those analyzed at the first model level above surface $(\sim 50 \mathrm{~m})$ at 1940 UTC from (c),(d) EXPZ and (e),(f) EXPZZDR. Areas not identified as rain in the observations are noted by gray pixels in (a),(b). Reflectivity increments of $20 \mathrm{dBZ}$ are contoured in black on all panels.

They found that the size sorting of hail aloft contributed more to the $Z_{\mathrm{DR}}$ arc near the surface than the size sorting of rain, as well as to a broader area of increased $Z_{\mathrm{DR}}$ in the right-forward flank referred to as the $Z_{\mathrm{DR}}$ shield. Overall, the estimate of the model microphysical states above the melting layer is believed to be improved in EXPZZDR compared to EXPZ, even though $Z_{\mathrm{DR}}$ values are not assimilated in this region.

It should be noted that the hail aloft, which helps regulate the $Z_{\mathrm{DR}}$ arc at the surface, may fall in distinct episodes. This can lead to breaks in the $Z_{\mathrm{DR}}$ arc, specifically if the hail is large and dry and the associated $Z_{\mathrm{DR}}$ values are near zero (Picca et al. 2010; Van Den Broeke et al. 2008; Tanamachi and Heinselman 2016). These episodes were not seen during the evaluation period, especially compared to the substantial decrease in $Z_{\mathrm{DR}}$ seen in Tanamachi and Heinselman (2016). The observations for our case suggest the hail in the storms was wet. However, if this did occur, the observation operators would be able to account for the difference in small, wet hail and large, dry hail, including for sizes in the Mie scattering regime (Jung et al. 2010a).

\section{Conclusions and discussion}

In this study, polarimetric radar observations are assimilated directly for a real supercell case using the ensemble Kalman filter (EnKF) for the first time, with a double-moment (DM) microphysics (MP) scheme and forward observation operators that employ full T-matrix scattering amplitude calculations. The Oklahoma tornado outbreak of 20 May 2013, specifically the NewcastleMoore, Oklahoma, tornadic supercell, is used as a test case. Two experiments are performed: "EXPZ," which assimilates $Z$ and $V_{r}$, and "EXPZZDR," which assimilates $Z_{\mathrm{DR}}$ in addition to $Z$ and $V_{r} . Z_{\mathrm{DR}}$ observations are only assimilated below $2 \mathrm{~km}$ above ground level (AGL) to avoid assimilating observations near or above the melting layer for which observation operators have large uncertainties.

The analyzed $Z_{\mathrm{DR}}$ in EXPZZDR shows a better fit to observed $Z_{\mathrm{DR}}$ compared to that in EXPZ. The analyzed $Z_{\mathrm{DR}}$ in EXPZZDR is higher compared to EXPZ near the region known as the $Z_{\mathrm{DR}}$ arc (Kumjian and Ryzhkov 2008) in the observations, while there are regions of lower $Z_{\mathrm{DR}}$ farther downshear in the forward flank of the supercell. However, the $Z_{\mathrm{DR}}$ values near the observed $Z_{\mathrm{DR}}$ arc are underestimated in both analyses and their orientation is displaced to the north, potentially due to excessive size sorting noted with the Milbrandt and Yau DM MP scheme (Milbrandt and Yau 2005b). Additionally, the analyzed $Z$ in EXPZZDR is not substantially different compared to EXPZ and the observations, indicating that the assimilation of $Z_{\mathrm{DR}}$ improves the model particle size 
EXPZ
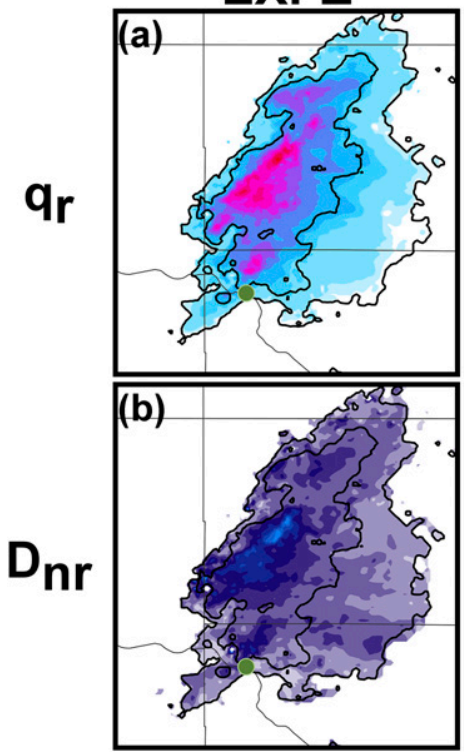

EXPZZDR
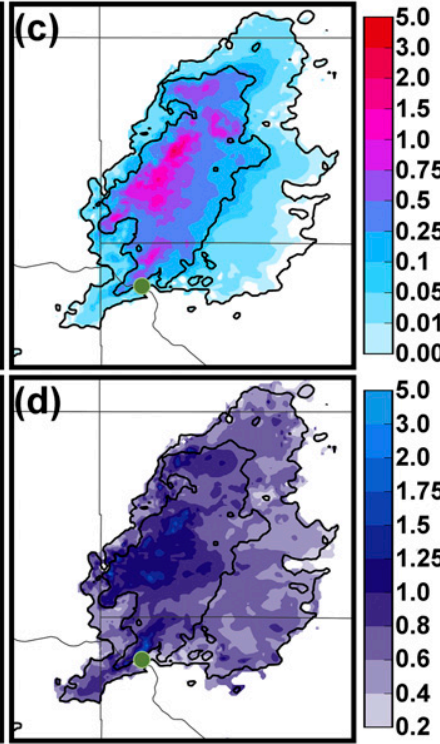

DIF ZZDR - Z
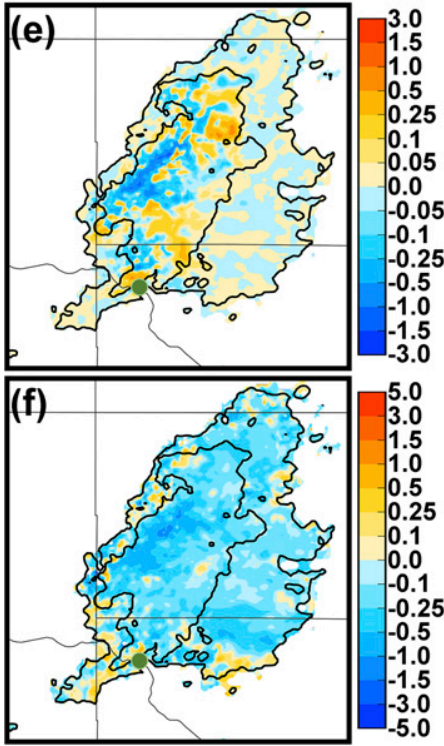

FIG. 13. (a) Rainwater mixing ratio $\left(\mathrm{g} \mathrm{kg}^{-1}\right)$ and (b) mean mass diameter ( $\mathrm{mm}$ ) at $2 \mathrm{~km}$ AGL from the ensemble mean analyses at 1940 UTC for EXPZ and (c),(d) EXPZZDR as well as the (e),(f) difference between EXPZZDR and EXPZ for both fields. Reflectivity increments of $20 \mathrm{dBZ}$ for EXPZ and EXPZZDR are contoured in black in the first two columns and for EXPZZDR in the rightmost column. The green dot marks the location of the updraft based on a local maximum in vertical velocity.

distributions (PSDs) (and hence the microphysical states) relative to the observed microphysical states while still fitting similar $Z$ values as in EXPZ. More specifically, assimilated $Z_{\mathrm{DR}}$ observations improve the estimate of the storm microphysical states in ways not noticeable in the $Z$ field alone. Vertical cross sections of $Z_{\mathrm{DR}}$ reveal that assimilating $Z_{\mathrm{DR}}$ has an impact well above $2 \mathrm{~km}$ AGL where $Z_{\mathrm{DR}}$ is not assimilated - this is possible through the spread of observation information via ensemble covariances and through model state interactions within the EnKF data assimilation (DA) cycles. The vertical distribution of $Z_{\mathrm{DR}}$ near the updraft better matches the observations in EXPZZDR than in EXPZ. There is also a small but noticeable increase in $Z_{\mathrm{DR}}$ values in EXPZZDR above the melting layer collocated with the $Z_{\mathrm{DR}}$ column (Kumjian and Ryzhkov 2008) in the observations.

Rainwater mean mass diameter $\left(D_{\mathrm{nr}}\right)$ and total rain number concentration $\left(N_{\mathrm{tr}}\right)$ are evaluated at the surface, which demonstrates the positive impact of assimilating $Z_{\mathrm{DR}}$ observations on the estimate of the model microphysical states. High $D_{\mathrm{nr}}$ values are present in EXPZZDR in regions where observed $Z_{\mathrm{DR}}$ is high (and vice versa), more so than in EXPZ. The patterns in $D_{\mathrm{nr}}$ approaching the $Z_{\mathrm{DR}}$ arc in the forward flank of the Moore storm in EXPZZDR also agree well with $D_{\text {nr }}$ retrieved from $Z_{\mathrm{DR}}$ observations, although the observation-derived $D_{\mathrm{nr}}$ values are higher overall. Additionally, $N_{\mathrm{tr}}$ is higher in regions of low observed $Z_{\mathrm{DR}}$ in EXPZZDR compared to EXPZ, and better matches patterns of $N_{\text {tr }}$ retrieved from observations.

There are notable differences in the hail size distribution above 2-km between EXPZZDR and EXPZ despite the fact $Z_{\mathrm{DR}}$ is not assimilated above $2 \mathrm{~km}$. The hail mean mass diameter $\left(D_{\mathrm{nh}}\right)$ in EXPZZDR has a negative gradient along the right-forward flank of the supercell, with values decreasing farther from the updraft, more so than in EXPZ. The gradient in EXPZZDR matches the schematic of Fig. 17 in Dawson et al. (2014), where size sorting of hail aloft was found to have a more significant impact than the size sorting of rain on the size distribution of oblate raindrops at the surface that compose the $Z_{\mathrm{DR}}$ arc. Again, the improvement in the estimate of the microphysical states by the assimilation of $Z_{\mathrm{DR}}$ near the surface in EXPZZDR appears to be spread well aloft within the storm by the covariance structures in the EnKF, and through state interactions during model integration within the EnKF DA cycles. Also, the noted improvement in the midlevel mesocyclone in EXPZZDR follows previous studies that demonstrated a positive correlation between higher values of $Z_{\mathrm{DR}}$ in the $Z_{\mathrm{DR}}$ column and mesocyclone strength, which increases hail growth aloft.

EnKF assimilation of $Z_{\mathrm{DR}}$ improves the fit of analyzed $Z_{\mathrm{DR}}$ to observations and favorably adjusts the 


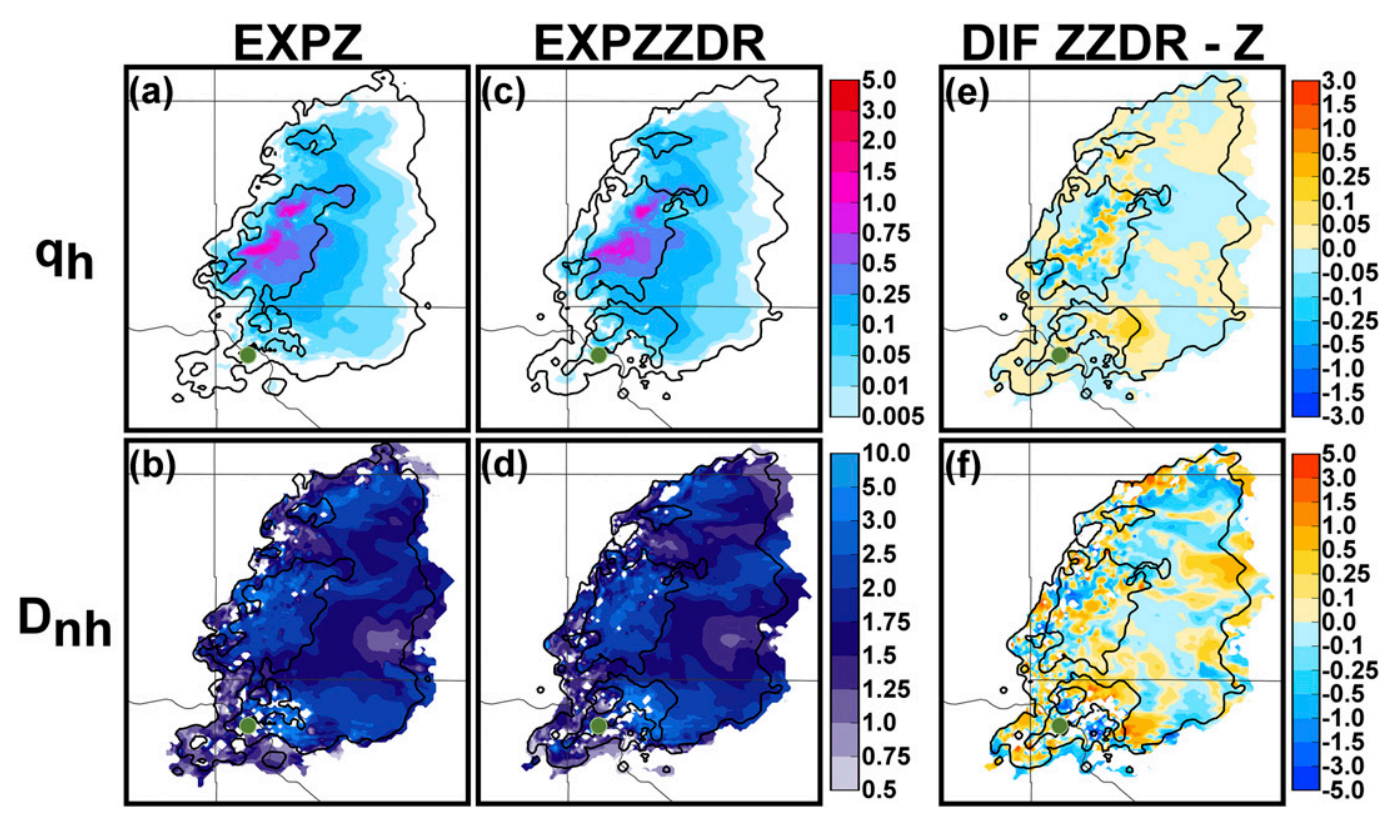

FIG. 14. As in Fig. 13, but for hail at $4 \mathrm{~km}$ above ground level (AGL).

microphysical model state variables. However, there is still significant error in the magnitude of analyzed $Z$ and $Z_{\mathrm{DR}}$ values and in the patterns of values representing the structure of known polarimetric signatures. Based upon this study, we identify several areas for future research. First, additional study on topics related to cloud microphysics schemes is needed. Despite thorough testing of several different sets of assumed observation errors and model error treatment methods, there are still notable errors in the analyzed $Z$ and $Z_{\mathrm{DR}}$ fields. $Z$ and $Z_{\mathrm{DR}}$ are underestimated in the southern portion of the supercell forward flank and the orientation of the analyzed $Z_{\mathrm{DR}}$ arc is more easterly than that observed. Such differences are at least partially due to errors within the model MP scheme, including excessive size sorting. Microphysics parameterization errors will cause fast error growth during the forecast period in the DA cycles and large background forecast error is difficult to correct. For radar data assimilation using ensemblebased methods such as EnKF, the cross covariances among the microphysical and other state variables are also very important; large model errors can make such covariances unreliable. The assimilation of additional observations such as $Z_{\mathrm{DR}}$ provides more observational constraint to the analyzed state but does not eliminate impacts of model error. A triple-moment (TM) scheme and/or improved microphysical parameterizations, such as one that predicts hydrometeor water fractions, are expected to improve the results. Use of a TM scheme may also improve quantitative comparisons between the EnKF-analyzed microphysical state and the radar retrieved values where a nonzero shape parameter was used. However, additional improvements are needed beyond simply using schemes with more predicted moments or hydrometeor types. The distribution and magnitude of $Z_{\mathrm{DR}}$ values in EXPZZDR around the observed $Z_{\mathrm{DR}}$ column above the freezing level is over and underestimated, respectively. This feature is connected not only to oblate raindrops but also to melting hail. A future study, based on Labriola et al. (2017), will investigate to what extent the use of triple-moment and variable density rimed-ice (low density graupel to high density hail) schemes can improve hail prediction; similar research could be beneficial for all hydrometeor types.

Additionally, further research on the uncertainties due to assumptions made in the forward operators for polarimetric variables is needed. The assimilation of observed $Z_{\mathrm{DR}}$ values in this case is limited to $2 \mathrm{~km}$ AGL or less, well below the melting layer, due to the increased uncertainty when modeling mixed-phase hydrometeors in the operators that are not predicted by the model microphysics scheme. The melting height in the model is also noted to be below the $0^{\circ}$ isotherm because melting is maximized where $q_{r}$ and $q_{h}$ are comparable in the current melting parameterization; assimilation of $Z_{\mathrm{DR}}$ above $2 \mathrm{~km}$ along with enhancements to the melting treatment could help improve this. A follow-up study to Johnson et al. (2016) will seek to improve the current forward operators when simulating polarimetric variables for ice and mixedphase hydrometeors. Further research is also needed 
EXPZ

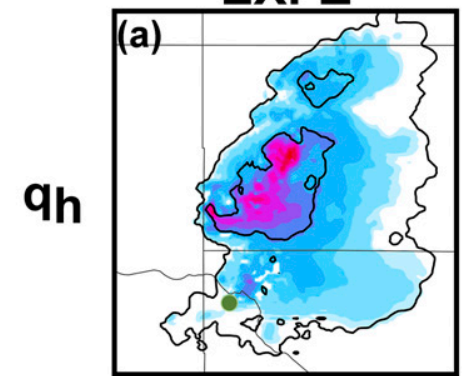

EXPZZDR
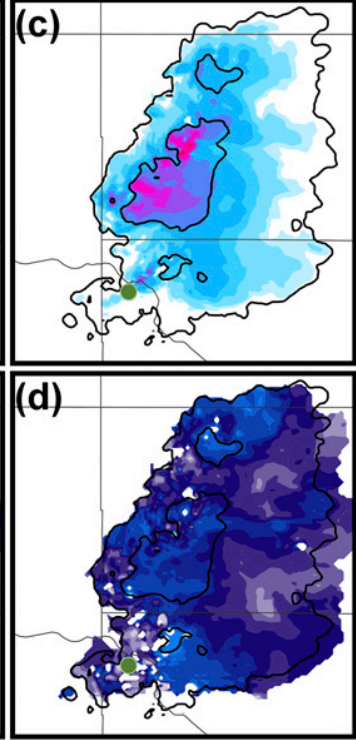

DIF ZZDR - Z
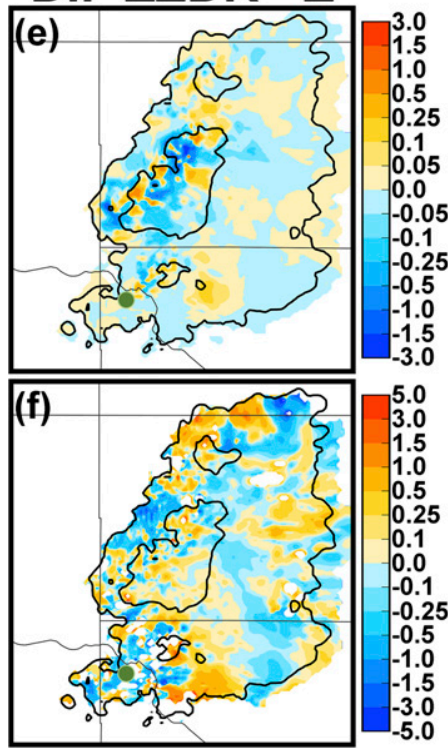

FIG. 15. As in Fig. 14, but for hail at $6 \mathrm{~km}$ above ground level (AGL).

on the observation errors used for polarimetric variables. This study found that a lower observation error for $Z_{\mathrm{DR}}$ improved the fit of analyzed $Z_{\mathrm{DR}}$ to the observations but negatively affected the fit of $Z$. Additional experiments are needed to find an optimal balance between the errors used for each type of observation. Future studies are also needed to assess the impact of other polarimetric variables, including $K_{\mathrm{DP}}$, have on the estimate of the model microphysical states. Finally, this study does not include forecasts initialized from the improved EnKF analyses. Future work will investigate how significant the impact is on forecasts initialized from the improved estimated microphysical states and how long any benefit persists into the forecasts.

Acknowledgments. This work was primarily supported by NSF Grant AGS-1046171. The first and fifth authors were also supported by NOAA Grant NA11OAR4320072. The second and fourth authors were also supported by NSF Grant AGS-1261776. The third author is also partially supported by a research grant of "Development of a Polarimetric Radar Data Simulator for Local Forecasting Model" by the Korea Meteorological Administration and NSF Grant AGS1261776. Computing was performed primarily on the Stampede system at the Texas Advanced Computing Center (TACC), part of the XSEDE resources. We would also like to thank the three anonymous reviewers whose insightful comments and critiques helped strengthen the manuscript.

\section{REFERENCES}

Anderson, J. L., 2001: An ensemble adjustment Kalman filter for data assimilation. Mon. Wea. Rev., 129, 2884-2903, https:// doi.org/10.1175/1520-0493(2001)129<2884:AEAKFF> 2.0.CO;2.

Balakrishnan, N., and D. S. Zrnić, 1990: Use of polarization to characterize precipitation and discriminate large hail. J. Atmos. Sci., 47, 1525-1540, https://doi.org/10.1175/1520-0469(1990) 047<1525:UOPTCP $>2.0$. CO;2.

Brandes, E. A., J. Vivekanandan, J. D. Tuttle, and C. J. Kessinger, 1995: A study of thunderstorm microphysics with multiparameter radar and aircraft observations. Mon. Wea. Rev., 123, 3129-3143, https://doi.org/10.1175/1520-0493(1995)123<3129: ASOTMW $>2.0 . \mathrm{CO} ; 2$.

—, G. Zhang, and J. Vivekanandan, 2002: Experiments in rainfall estimation with a polarimetric radar in a subtropical environment. J. Appl. Meteor., 41, 674-685, https://doi.org/ 10.1175/1520-0450(2002)041<0674:EIREWA > 2.0.CO;2.

,$- \ldots$, and - , 2003: An evaluation of a drop distributionbased polarimetric radar rainfall estimator. J. Appl. Meteor., 42, 652-660, https://doi.org/10.1175/1520-0450(2003)042<0652: AEOADD > 2.0.CO;2; Corrigendum, 44, 186, https://doi.org/ 10.1175/1520-0450(2005)44<186:C > 2.0.CO;2

_ K. Ikeda, G. Zhang, M. Schönhuber, and R. M. Rasmussen, 2007: A statistical and physical description of hydrometeor distributions in Colorado snowstorms using a video disdrometer. J. Appl. Meteor. Climatol., 46, 634-650, https://doi.org/10.1175/ JAM2489.1.

Brewster, K., M. Hu, M. Xue, and J. Gao, 2005: Efficient assimilation of radar data at high resolution for short-range numerical weather prediction. Preprints, WWRP Int. Symp. Nowcasting Very Short Range Forecasting, Tolouse, France, WMO, 3.06, http://twister.ou.edu/papers/BrewsterWWRP_ Nowcasting.pdf.

Bringi, V. N., and V. Chandrasekar, 2001: Polarimetric Doppler Weather Radar. Cambridge University Press, 636 pp. 
Brown, B. G., 2001: Verification of Precipitation Forecasts: A Survey of Methodology. Part II: Verification of Probability Forecasts at Points. National Center for Atmospheric Research, 20 pp.

Burgess, D. W., and Coauthors, 2014: 20 May 2013 Moore, Oklahoma, tornado: Damage survey and analysis. Wea. Forecasting, 29, 12291237, https://doi.org/10.1175/WAF-D-14-00039.1.

Cao, Q., G. Zhang, E. Brandes, T. Schuur, A. Ryzhkov, and K. Ikeda, 2008: Analysis of video disdrometer and polarimetric radar data to characterize rain microphysics in Oklahoma. J. Appl. Meteor. Climatol., 47, 2238-2255, https:// doi.org/10.1175/2008JAMC1732.1.

Carlin, J. T., J. Gao, J. C. Snyder, and A. V. Ryzhkov, 2017: Assimilation of ZDR columns for improving the spinup and forecast of convective storms in storm-scale models: Proof-ofconcept experiments. Mon. Wea. Rev., 145, 5033-5057, https:// doi.org/10.1175/MWR-D-17-0103.1.

Chang, W., K. Chung, L. Fillion, and S. Baek, 2014: Radar data assimilation in the Canadian high-resolution ensemble Kalman filter system: Performance and verification with real summer cases. Mon. Wea. Rev., 142, 2118-2138, https://doi.org/10.1175/ MWR-D-13-00291.1.

Dawson, D. T., II, M. Xue, J. A. Milbrandt, and M. K. Yau, 2010: Comparison of evaporation and cold pool development between single-moment and multimoment bulk microphysics schemes in idealized simulations of tornadic thunderstorms. Mon. Wea. Rev., 138, 1152-1171, https://doi.org/10.1175/ 2009MWR2956.1.

_ , E. R. Mansell, Y. Jung, L. J. Wicker, M. R. Kumjian, and M. Xue, 2014: Low-level ZDR signatures in supercell forward flanks: The role of size sorting and melting of hail. J. Atmos. Sci., 71, 276-299, https://doi.org/10.1175/JAS-D-13-0118.1.

_- M. Xue, A. Shapiro, and J. A. Milbrandt, 2015: Sensitivity of real-data simulations of the 3 May 1999 Oklahoma City tornadic supercell and associated tornadoes to multimoment microphysics. Part I: Storm- and tornado-scale numerical forecasts. Mon. Wea. Rev., 143, 2241-2265, https://doi.org/ 10.1175/MWR-D-14-00279.1.

Doswell, C. A., H. E. Brooks, and N. Doztek, 2009: On the implementation of the enhanced Fujita scale in the USA. Atmos. Res., 93, 554-563, https://doi.org/10.1016/j.atmosres.2008.11.003.

Doviak, R., and D. Zrnić, 1993: Doppler Radar and Weather Observations. 2nd ed. Academic Press, 562 pp.

Dowell, D. C., and L. J. Wicker, 2009: Additive noise for stormscale ensemble data assimilation. J. Atmos. Oceanic Technol., 26, 911-927, https://doi.org/10.1175/2008JTECHA1156.1.

Dudhia, J., 1989: Numerical study of convection observed during the winter monsoon experiment using a mesoscale, two-dimensional model. J. Atmos. Sci., 46, 3077-3107, https://doi.org/10.1175/15200469(1989)046<3077:NSOCOD>2.0.CO;2.

Evensen, G., 1994: Sequential data assimilation with a nonlinear quasi-geostrophic model using Monte Carlo methods to forecast error statistics. J. Geophys. Res., 99, 10143-10162, https://doi.org/10.1029/94JC00572.

_ 2003: The ensemble Kalman filter: Theoretical formulation and practical implementation. Ocean Dyn., 53, 343-367, https://doi.org/10.1007/s10236-003-0036-9.

Friedrich, K., U. Germann, and P. Tabary, 2009: Influence of ground clutter contamination on polarimetric radar parameters. J. Atmos. Oceanic Technol., 26, 251-269, https://doi.org/ 10.1175/2008JTECHA1092.1.

Gaspari, G., and S. E. Cohn, 1999: Construction of correlation functions in two and three dimensions. Quart. J. Roy. Meteor. Soc., 125, 723-757, https://doi.org/10.1002/qj.49712555417.
Gourley, J. J., P. Tabary, and J. Parent du Chatelet, 2007: A fuzzy logic algorithm for the separation of precipitating from nonprecipitating echoes using polarimetric radar observations. J. Atmos. Oceanic Technol., 24, 1439-1451, https://doi.org/ 10.1175/JTECH2035.1.

Hubbert, J., V. N. Bringi, L. D. Carey, and S. Bolen, 1998: CSU-CHILL polarimetric radar measurements from a severe hail storm in Eastern Colorado. J. Appl. Meteor., 37, 749-775, https://doi.org/10.1175/1520-0450(1998)037<0749:CCPRMF> 2.0.CO;2.

Johnson, M., Y. Jung, D. Dawson, and M. Xue, 2016: Comparison of simulated polarimetric signatures in idealized supercell storms using two-moment bulk microphysics schemes in WRF. Mon. Wea. Rev., 144, 971-996, https://doi.org/10.1175/MWRD-15-0233.1.

Jung, Y., G. Zhang, and M. Xue, 2008a: Assimilation of simulated polarimetric radar data for a convective storm using ensemble Kalman filter. Part I: Observation operators for reflectivity and polarimetric variables. Mon. Wea. Rev., 136, 2228-2245, https://doi.org/10.1175/2007MWR2083.1.

— M. Xue, G. Zhang, and J. Straka, 2008b: Assimilation of simulated polarimetric radar data for a convective storm using ensemble Kalman filter. Part II: Impact of polarimetric data on storm analysis. Mon. Wea. Rev., 136, 2246-2260, https:// doi.org/10.1175/2007MWR2288.1.

$\longrightarrow, \ldots$, and $\_, 2010 \mathrm{a}$ : Simulations of polarimetric radar signatures of a supercell storm using a two-moment bulk microphysics scheme. J. Appl. Meteor. Climatol., 49, 146-163, https://doi.org/10.1175/2009JAMC2178.1.

,-- , and $-2010 \mathrm{~b}$ : Simultaneous estimation of microphysical parameters and the atmospheric state using simulated polarimetric radar data and an ensemble Kalman filter in the presence of an observation operator error. Mon. Wea. Rev., 138, 539-562, https://doi.org/10.1175/2009MWR2748.1.

$\_, \ldots$, and M. Tong, 2012: Ensemble Kalman filter analyses of the 29-30 May 2004 Oklahoma tornadic thunderstorm using one- and two-moment bulk microphysics schemes, with verification against polarimetric data. Mon. Wea. Rev., 140, 14571475, https://doi.org/10.1175/MWR-D-11-00032.1.

Kalnay, E., 2002: Atmospheric Modeling, Data Assimilation, and Predictability. Cambridge University Press, 341 pp.

Kessler, E., 1969: On the Distribution and Continuity of Water Substance in Atmospheric Circulations. Meteor. Monogr., No. 32, Amer. Meteor. Soc., 84 pp.

Kong, F., 2013: 2013 CAPS Spring Forecast Experiment Program Plan. NOAA, 24 pp., https://hwt.nssl.noaa.gov/Spring_2013/ SpringProgram2013_Plan-v5.pdf.

Kumjian, M. R., 2013: Principles and applications of dualpolarization weather radar. Part III: Artifacts. J. Oper. Meteor., 1, 265-274, https://doi.org/10.15191/nwajom.2013.0121.

_ , and A. V. Ryzhkov, 2008: Polarimetric signatures in supercell thunderstorms. J. Appl. Meteor. Climatol., 47, 1940-1961, https://doi.org/10.1175/2007JAMC1874.1.

— and - 2012: The impact of size sorting on the polarimetric radar variables. J. Atmos. Sci., 69, 2042-2060, https://doi.org/ 10.1175/JAS-D-11-0125.1.

— A. P. Khain, N. Benmoshe, E. Ilotoviz, A. V. Ryzhkov, and V. T. Phillips, 2014: The anatomy and physics of ZDR columns: Investigating a polarimetric radar signature with a spectral bin microphysical model. J. Appl. Meteor. Climatol., 53, 1820-1843, https://doi.org/10.1175/JAMC-D-13-0354.1.

Kurdzo, J. M., D. J. Bodine, B. L. Cheong, and R. D. Palmer, 2015: High-temporal resolution polarimetric X-band doppler radar 
observations of the 20 May 2013 Moore, Oklahoma, tornado. Mon. Wea. Rev., 143, 2711-2735, https://doi.org/ 10.1175/MWR-D-14-00357.1.

Labriola, J., N. Snook, Y. Jung, B. Putnam, and M. Xue, 2017: Ensemble hail prediction for the storms of 10 May 2010 in south-central Oklahoma using single- and double-moment microphysical schemes. Mon. Wea. Rev., 145, 4911-4936, https://doi.org/10.1175/MWR-D-17-0039.1.

Lakshmanan, V., C. Karstens, J. Krause, and L. Tang, 2014: Quality control of weather radar data using polarimetric variables. J. Atmos. Oceanic Technol., 31, 1234-1249, https://doi.org/ 10.1175/JTECH-D-13-00073.1.

Larson, V. E., J.-C. Golaz, H. Jiang, and W. R. Cotton, 2005: Supplying local microphysics parameterizations with information about subgrid variability: Latin hypercube sampling. J. Atmos. Sci., 62, 4010-4026, https://doi.org/10.1175/JAS3624.1.

Li, X., and J. R. Mecikalski, 2010: Assimilation of the dualpolarization Doppler radar data for a convective storm with a warm-rain radar forward operator. J. Geophys. Res., 115, D16208, https://doi.org/10.1029/2009JD013666.

— , and - 2012: Impact of the dual-polarization Doppler radar data on two convective storms with a warm-rain radar forward operator. Mon. Wea. Rev., 140, 2147-2167, https:// doi.org/10.1175/MWR-D-11-00090.1.

—,- , and D. Posselt, 2017: An ice-phase microphysics forward model and preliminary results of polarimetric radar data assimilation. Mon. Wea. Rev., 145, 683-708, https://doi.org/ 10.1175/MWR-D-16-0035.1.

Liao, L., R. Meneghini, A. Tokay, and L. F. Bliven, 2016: Retrieval of snow properties for $\mathrm{Ku}$ - and $\mathrm{Ka}$-band dual-frequency radar. J. Appl. Meteor. Climatol., 55, 1845-1858, https://doi.org/ 10.1175/JAMC-D-15-0355.1.

Lin, Y.-L., R. D. Farley, and H. D. Orville, 1983: Bulk parameterization of the snow field in a cloud model. J. Climate Appl. Meteor., 22, 1065-1092, https://doi.org/10.1175/1520-0450(1983) 022<1065:BPOTSF $>2.0 . \mathrm{CO} ; 2$.

Loney, M. L., D. S. Zrnić, J. M. Straka, and A. V. Ryzhkov, 2002: Enhanced polarimetric radar signatures above the melting level in a supercell storm. J. Appl. Meteor., 41, 1179-1194, https://doi.org/10.1175/1520-0450(2002)041<1179:EPRSAT> 2.0.CO;2.

Lorenz, E. N., 1969: Atmospheric predictability as revealed by naturally occurring analogues. J. Atmos. Sci., 26, 636-646, https://doi.org/10.1175/1520-0469(1969)26<636:APARBN> 2.0.CO;2.

Mason, I. B., 1982: A model for the assessment of weather forecasts. Aust. Meteor. Mag., 30, 291-303.

Mason, S. J., and N. E. Graham, 1999: Conditional probabilities, relative operating characteristics, and relative operating levels. Wea. Forecasting, 14, 713-725, https://doi.org/10.1175/ 1520-0434(1999)014<0713:CPROCA >2.0.CO;2.

Milbrandt, J. A., and M. K. Yau, 2005a: A multi-moment bulk microphysics parameterization. Part II: A proposed threemoment closure and scheme description. J. Atmos. Sci., 62 , 3065-3081, https://doi.org/10.1175/JAS3535.1.

$\longrightarrow$, and,$- 2005 \mathrm{~b}$ : A multi-moment bulk microphysics parameterization. Part I: Aanlysis of the role of the spectral shape parameter. J. Atmos. Sci., 62, 3051-3064, https://doi.org/ 10.1175/JAS3534.1.

Morrison, H., and J. Milbrandt, 2011: Comparison of two-moment bulk microphysics schemes in idealized supercell thunderstorm simulations. Mon. Wea. Rev., 139, 1103-1130, https:// doi.org/10.1175/2010MWR3433.1.
- , and — 2015: Parameterization of cloud microphysics based on the prediction of bulk ice particle properties. Part I: Scheme description and idealized tests. J. Atmos. Sci., 72, 287311, https://doi.org/10.1175/JAS-D-14-0065.1.

, J. A. Curry, and V. I. Khvorostyanov, 2005: A new doublemoment microphysics parameterization for application in cloud and climate models. Part I: Description. J. Atmos. Sci., 62, 1665-1677, https://doi.org/10.1175/JAS3446.1.

Park, H. S., A. V. Ryzhkov, D. S. Zrnić, and K.-E. Kim, 2009: The hydrometeor classification algorithm for the polarimetric WSR-88D: Description and application to an MCS. Wea. Forecasting, 24, 730-748, https://doi.org/10.1175/ 2008W AF2222205.1.

Picca, J. C., M. R. Kumjian, and A. V. Ryzhkov, 2010: Z ${ }_{\mathrm{DR}}$ columns as a predictive tool for hail growth and storm evolution. 25th Conf. on Severe Local Storms, Denver, CO, Amer. Meteor. Soc., 11.3, https://ams.confex.com/ams/25SLS/techprogram/ paper_175750.htm.

Pielke, R. A., Sr., and Coauthors, 2006: A new paradigm for parameterizations in numerical weather prediction and other atmospheric models. Natl. Wea. Dig., 30, 93-99.

Putnam, B. J., M. Xue, Y. Jung, N. Snook, and G. Zhang, 2014: The analysis and prediction of microphysical states and polarimetric radar variables in a mesoscale convective system using double-moment microphysics, multinetwork radar data, and the ensemble Kalman filter. Mon. Wea. Rev., 142, 141-162, https://doi.org/10.1175/MWR-D-13-00042.1.

, G. Zhang, and F. Kong, 2017a: Simulation of polarimetric radar variables from 2013 CAPS spring experiment storm scale ensemble forecasts and evaluation of microphysics schemes. Mon. Wea. Rev., 145, 49-73, https:// doi.org/10.1175/MWR-D-15-0415.1.

,,,--- N. A. Snook, and G. Zhang, 2017b: Ensemble probabilistic prediction of a mesoscale convective system and associated polarimetric radar variables using single-moment and double-moment microphysics schemes and EnKF radar data assimilation. Mon. Wea. Rev., 145, 2257-2279, https:// doi.org/10.1175/MWR-D-16-0162.1.

ROC, 2013: WSR-88D dual polarization deployment progress. NOAA, 6 pp., http://www.roc.noaa.gov/WSR88D/PublicDocs/ DualPol/DPstatus.pdf.

Rutledge, S. A., and P. V. Hobbs, 1983: The mesoscale and microscale structure and organization of clouds and precipitation in midlatitude cyclones. Part VIII: A model for the feederseeder process in warm frontal rainbands. J. Atmos. Sci., 40, 1185-1206, https://doi.org/10.1175/1520-0469(1983)040<1185: TMAMSA $>2.0 . \mathrm{CO} ; 2$.

Ryzhkov, A., 2006: The effect of nonuniform beam filling on the quality of radar polarimetric data. Proc. Fourth European Conf. on Radar in Meteorology and Hydrology (ERAD), Barcelona, Spain, http://www.crahi.upc.edu/ERAD2006/.

Ryzhkov, A. V., and D. S. Zrnić, 1998: Polarimetric rainfall estimation in the presence of anomalous propagation. J. Atmos. Oceanic Technol., 15, 1320-1330, https://doi.org/10.1175/15200426(1998)015<1320:PREITP>2.0.CO;2.

— S. E. Giangrande, V. M. Melnikov, and T. J. Schuur, 2005: Calibration issues of dual-polarization radar measurements. J. Atmos. Oceanic Technol., 22, 1138-1155, https://doi.org/ 10.1175/JTECH1772.1.

Scharfenberg, K. A., and Coauthors, 2005: The joint polarization experiment: Polarimetric radar in forecasting and warning decision making. Wea. Forecasting, 20, 775-788, https://doi.org/ 10.1175/WAF881.1. 
Seliga, T. A., and V. N. Bringi, 1976: Potential use of radar differential reflectivity measurements at orthogonal polarizations for measuring precipitation. J. Appl. Meteor., 15, 69-76, https://doi.org/10.1175/1520-0450(1976)015<0069:PUORDR > 2.0.CO;2.

Snook, N., M. Xue, and Y. Jung, 2011: Analysis of a tornadic mesoscale convective vortex based on ensemble Kalman filter assimilation of CASA X-band and WSR-88D radar data. Mon. Wea. Rev., 139, 3446-3468, https://doi.org/10.1175/MWR-D10-05053.1.

,-- , and -2013 : Impacts of assumed observation errors in EnKF analyses and ensemble forecasts of a tornadic mesoscale convective system. 17th Conf. on Integrated Observing and Assimilation Systems for the Atmosphere, Oceans, and Land Surface (IOAS-AOLS), Austin, TX, Amer. Meteor. Soc., 13.2, https://ams.confex.com/ams/93Annual/webprogram/ Paper219933.html.

,-- , and,- 2015 : Multi-scale EnKF assimilation of radar and conventional observations and ensemble forecasting for a tornadic mesoscale convective system. Mon. Wea. Rev., 143, 1035-1057, https://doi.org/10.1175/MWR-D-13-00262.1.

— , Y. Jung, J. Brotzge, B. Putnam, and M. Xue, 2016: Prediction and ensemble forecast verification of hail in the supercell storms of 20 May 2013. Wea. Forecasting, 31, 811-825, https:// doi.org/10.1175/WAF-D-15-0152.1.

Snyder, C., and F. Zhang, 2003: Assimilation of simulated Doppler radar observations with an ensemble Kalman filter. Mon. Wea. Rev., 131, 1663-1677, https://doi.org/10.1175//2555.1.

Snyder, J. C., A. V. Ryzhkov, M. R. Kumjian, A. P. Khain, and J. Picca, 2015: A ZDR column detection algorithm to examine convective storm updrafts. Wea. Forecasting, 30, 1819-1844, https://doi.org/10.1175/WAF-D-15-0068.1.

SPC, 2016: SPC filtered storm reports for 5/20/2013. Accessed 4 May 2017, a http://www.spc.noaa.gov/climo/reports/130520_ rpts.html.

Sun, J., and N. A. Crook, 1997: Dynamical and microphysical retrieval from Doppler radar observations using a cloud model and its adjoint. Part I: Model development and simulated data experiments. J. Atmos. Sci., 54, 1642-1661, https://doi.org/ 10.1175/1520-0469(1997)054<1642:DAMRFD > 2.0.CO;2.

Tanamachi, R. L., and P. L. Heinselman, 2016: Rapid-scan, polarimetric observations of central Oklahoma severe storms on 31 May 2013. Wea. Forecasting, 31, 19-42, https://doi.org/ 10.1175/WAF-D-15-0111.1.

Thompson, G., P. R. Field, R. M. Rasmussen, and W. D. Hall, 2008: Explicit forecasts of winter precipitation using an improved bulk microphysics scheme. Part II: Implementation of a new snow parameterization. Mon. Wea. Rev., 136, 5095-5115, https://doi.org/10.1175/2008MWR2387.1.

Tong, M., and M. Xue, 2005: Ensemble Kalman filter assimilation of Doppler radar data with a compressible nonhydrostatic model: OSS experiments. Mon. Wea. Rev., 133, 1789-1807, https://doi.org/10.1175/MWR2898.1.

— , and — , 2008: Simultaneous estimation of microphysical parameters and atmospheric state with radar data and ensemble square root Kalman filter. Part I: Sensitivity analysis and parameter identifiability. Mon. Wea. Rev., 136, 1630-1648, https://doi.org/10.1175/2007MWR2070.1.

Van Den Broeke, M. S., J. M. Straka, and E. N. Rasmussen, 2008: Polarimetric radar observations at low levels during tornado life cycles in a small sample of classic southern plains supercells. J. Appl. Meteor. Climatol., 47, 1232-1247, https://doi.org/ 10.1175/2007JAMC1714.1.
Vivekanandan, J., W. M. Adams, and V. N. Bringi, 1991: Rigorous approach to polarimetric radar modeling of hydrometeor orientation distributions. J. Appl. Meteor., 30, 1053-1063, https://doi.org/10.1175/1520-0450(1991)030<1053:RATPRM > 2.0.CO;2.

Wacker, U., and A. Seifert, 2001: Evolution of rain water profiles resulting from pure sedimentation: Spectral vs. parameterized description. Atmos. Res., 58, 19-39, https://doi.org/10.1016/ S0169-8095(01)00081-3.

Wang, H., T. Auligne, and H. Morrison, 2012: Impact of microphysics scheme complexity on the propagation of initial perturbations. Mon. Wea. Rev., 140, 2287-2296, https://doi.org/ 10.1175/MWR-D-12-00005.1.

Wheatley, D. M., N. Yussouf, and D. J. Stensrud, 2014: Ensemble Kalman filter analyses and forecasts of a severe mesoscale convective system using different choices of microphysics schemes. Mon. Wea. Rev., 142, 3243-3263, https://doi.org/ 10.1175/MWR-D-13-00260.1.

Whitaker, J. S., and T. M. Hamill, 2002: Ensemble data assimilation without perturbed observations. Mon. Wea. Rev., 130, 19131924, https://doi.org/10.1175/1520-0493(2002)130<1913: EDAWPO $>2.0 . \mathrm{CO} ; 2$.

$\longrightarrow$, and —, 2012: Evaluating methods to account for system errors in ensemble data assimilation. Mon. Wea. Rev., 140, 3078-3089, https://doi.org/10.1175/MWR-D-11-00276.1.

WSEC, 2006: A recommendation for an enhanced Fujita scale (EF-scale), revision 2. Wind Science and Engineering Center Rep., Texas Tech University, Lubbock, TX, 95 pp., http:// www.depts.ttu.edu/nwi/pubs/fscale/efscale.pdf.

Wu, B., J. Verlinde, and J. Sun, 2000: Dynamical and microphysical retrievals from Doppler radar observations of a deep convective cloud. J. Atmos. Sci., 57, 262-283, https://doi.org/ 10.1175/1520-0469(2000)057<0262:DAMRFD>2.0.CO;2.

Xue, M., K. K. Droegemeier, and V. Wong, 2000: The Advanced Regional Prediction System (ARPS) - A multiscale nonhydrostatic atmospheric simulation and prediction tool. Part I: Model dynamics and verification. Meteor. Atmos. Phys., $\mathbf{7 5}$, 161-193, https://doi.org/10.1007/s007030070003.

_ System (ARPS) - A multiscale nonhydrostatic atmospheric simulation and prediction tool. Part II: Model physics and applications. Meteor. Atmos. Phys., 76, 143-165, https:// doi.org/10.1007/s007030170027.

_ , D.-H. Wang, J.-D. Gao, K. Brewster, and K. K. Droegemeier, 2003: The Advanced Regional Prediction System (ARPS), storm-scale numerical weather prediction and data assimilation. Meteor. Atmos. Phys., 82, 139-170, https://doi.org/10.1007/ s00703-001-0595-6.

_- M. Tong, and K. K. Droegemeier, 2006: An OSSE framework based on the ensemble square root Kalman filter for evaluating the impact of data from radar networks on thunderstorm analysis and forecast. J. Atmos. Oceanic Technol., 23, 46-66, https://doi.org/10.1175/JTECH1835.1.

_ , Y. Jung, and G. Zhang, 2010: State estimation of convective storms with a two-moment microphysics scheme and an ensemble Kalman filter: Experiments with simulated radar data. Quart. J. Roy. Meteor. Soc., 136, 685-700, https://doi.org/ 10.1002/qj.593.

Yokota, S., H. Seko, M. Kunii, H. Yamauchi, and H. Niino, 2016: The tornadic supercell on the Kanto Plain on 6 May 2012: Polarimetric radar and surface data assimilation with EnKF and ensemble-based sensitivity analysis. Mon. Wea. Rev., 144, 3133-3157, https://doi.org/10.1175/MWR-D-15-0365.1. 
Yussouf, N., E. R. Mansell, L. J. Wicker, D. M. Wheatley, and D. J. Stensrud, 2013: The ensemble Kalman filter analyses and forecasts of the 8 May 2003 Oklahoma City tornado supercell storm using single and double moment microphysics schemes. Mon. Wea. Rev., 141, 3388-3412, https://doi.org/10.1175/ MWR-D-12-00237.1.

, D. C. Dowell, L. J. Wicker, K. H. Knopfmeier, and D. M. Wheatley, 2015: Storm-scale data assimilation and ensemble forecasts for the 27 April 2011 severe weather outbreak in Alabama. Mon. Wea. Rev., 143, 3044-3066, https://doi.org/ 10.1175/MWR-D-14-00268.1.

Zhang, G., 2015: Comments on "Describing the shape of raindrop size distributions using uncorrelated raindrop mass spectrum parameters." J. Appl. Meteor. Climatol., 54, 1970-1976, https:// doi.org/10.1175/JAMC-D-14-0210.1.

_ 2016: Weather Radar Polarimetry. CRC Press, 323 pp. , J. Vivekanandan, and E. Brandes, 2001: A method for estimating rain rate and drop size distribution from polarimetric radar measurements. IEEE Trans. Geosci. Remote Sens., 39, 830-841, https://doi.org/10.1109/36.917906.
, S. Luchs, A. Ryzhkov, M. Xue, L. Ryzhkova, and Q. Cao, 2011: Winter precipitation microphysics characterized by polarimetric radar and video disdrometer observations in central Oklahoma. J. Appl. Meteor. Climatol., 50, 1558-1570, https:// doi.org/10.1175/2011JAMC2343.1.

Zhang, Y., F. Zhang, D. J. Stensrud, and Z. Meng, 2015: Practical predictability of the 20 May 2013 tornadic thunderstorm event in Oklahoma: Sensitivity to synoptic timing and topographical influence. Mon. Wea. Rev., 143, 2973-2997, https://doi.org/ 10.1175/MWR-D-14-00394.1.

Zrnić, D. S., and A. V. Ryzhkov, 1998: Observations of insects and birds with a polarimetric radar. IEEE Trans. Geosci. Remote Sens., 36, 661-668, https://doi.org/10.1109/36.662746.

and -1999 : Polarimetry for weather surveillance radars. Bull. Amer. Meteor. Soc., 80, 389-406, https://doi.org/10.1175/ 1520-0477(1999)080<0389:PFWSR > 2.0.CO;2.

, V. N. Bringi, K. Aydin, N. Balakrishnan, V. Chandrasekar, and J. Hubbert, 1993: Polarimetric measurements in a severe hailstorm. Mon. Wea. Rev., 121, 2221-2238, https://doi.org/ 10.1175/1520-0493(1993)121<2223:PMIASH > 2.0.CO;2. 